\title{
Charity as Income Redistribution: A Model with Optimal Taxation, Status, and Social Stigma*
}

\author{
Thomas Aronsson a \\ Olof Johansson-Stenman b \\ Ronald Wendner $\mathrm{c}$ \\ a Department of Economics, Umeå School of Business, Economics and Statistics, Umeå \\ University, Sweden \\ b Department of Economics, School of Business, Economics and Law, University of \\ Gothenburg, Sweden \\ c Department of Economics, School of Business, Economics and Social Sciences, University \\ of Graz, Austria
}

September 2019

\begin{abstract}
In light of the increasing inequality in many countries, this paper analyzes redistributive charitable giving from the rich to the poor in a model of optimal nonlinear income taxation. Our framework integrates (i) public and private redistribution, (ii) the warm glow of giving and stigma of receiving charitable donations, and (iii) status concerns emanating from social comparisons with respect to charitable donations and private consumption. Whether charity should be taxed or supported largely depends on the relative strengths of the warm glow of giving and the stigma of receiving charity, respectively, and on the positional externalities caused by charitable donations. In addition, imposing stigma on the mimicker (which relaxes the self-selection constraint) strengthens the case for subsidizing charity. We also consider a case where the government is unable to target the charitable giving through a direct tax instrument, and we examine how the optimal marginal income tax structure should be adjusted in response to charitable giving. Numerical simulations demonstrate that the quantitative effects of the aforementioned mechanisms can be substantial.
\end{abstract}

Keywords: Conspicuous consumption, conspicuous charitable giving, social status, optimal income taxation, warm glow, stigma

JEL Classification: D03, D62, H21, H23

\footnotetext{
* The authors would like to thank participants at the workshop on Status, Social Beliefs, and Public Policy in Berlin 2017 and the IIPF conference in Glasgow 2019, as well as Spencer Bastani, Katharina Jenderny, Tobias König, Dylan Moore, and Tomas Sjögren for helpful comments and suggestions. Research grants from the Bank of Sweden Tercentenary Foundation, the Swedish Council for Working Life and Social Research, and the Swedish Tax Agency (all of them through project number RS10-1319:1), as well as from the Swedish Research Council (ref 2016-02371), are also gratefully acknowledged. The usual disclaimer applies.
} 


\section{Introduction}

While redistribution from the rich to the poor is a core governmental task in modern societies, income and wealth inequalities have increased sharply in many countries in recent decades, and are moreover typically expected to increase further. ${ }^{1}$ At the same time, people donate substantial amounts of money to charities, ${ }^{2}$ where currently only a small fraction serves the aim of helping the poor, suggesting that private charity could play an increasingly important rule over time to combat increasing inequalities. Since redistribution via the tax system is typically associated with social costs, due to incentive effects, one may wonder whether private redistribution through charitable giving ought to be encouraged via the tax system in order to play a more important role? Indeed, private charitable giving is already now explicitly supported in many countries, e.g., through tax deductions, effectively implying subsidization of charity relative to private consumption. Are there good reasons for this policy in cases where the charitable giving aims at reducing the inequality and/or poverty and, if so, under what conditions ${ }^{3}$ What would an optimal policy look like? The objective of the present paper is to answer these questions based on a model of optimal nonlinear income taxation in which there is redistribution both through the tax system and via charitable giving. In doing so, we will address a variety of mechanisms that may underlie society's tradeoff between charitable giving and private consumption such as the social status attached to donations and consumption, respectively, the warm glow of giving, and the stigma of receiving charity.

Our study contributes to the literature in at least four ways. First, we integrate redistributive charitable giving from donors to recipients into a discrete version of the Mirleesian optimal tax problem. This means that our approach differs in a fundamental way from earlier studies on charitable giving and optimal redistributive taxation, where charitable giving is typically described as voluntary contributions to a public good. Second, our study is also the first to analyze how an optimal tax policy ought to respond to the potential social stigma faced by the receivers of charity. That is, we do not only model the warm glow of giving on behalf of the donors, but also acknowledge a corresponding negative stigma effect for the receivers, such

\footnotetext{
${ }^{1}$ According to Saez and Zucman (2016), the share of total US wealth of the top 1 percent increased from below 25 percent in 1978 to above 40 percent in 2012; during the same period, the share of total wealth of the top 0.1 percent roughly tripled, while the share of the top 0.01 percent increased by more than a factor five.

${ }^{2}$ For example, the total U.S. charitable giving amounted to about 430 Billion USD or slightly above 2 percent of GDP in 2018 (Giving USA Foundation, 2019).

${ }^{3}$ We will solely focus on this kind of charitable giving since we believe that the value added in terms of additional insights of a more general setting in this regard would be limited in relation to the increased complexity. As described below, there are many policy-related papers focusing on charitable giving in terms of voluntary contributions to a public good.
} 
that the receivers would have preferred to obtain the same consumption possibilities through some other means than charity (in our case through the general income tax system). Third, together with our companion paper Aronsson, Johansson-Stenman, and Wendner (2019), the present study contributes by integrating simultaneous status motives for charitable giving and private consumption in the analysis (the difference between the two papers will be described below). Fourth, we distinguish between a case where the government is able to target the charitable giving through a direct tax instrument and a case where it is not, which will be described more thoroughly below.

While a broad perspective adds complexity, we believe that these elements and their interactions are crucial in order to understand the incentives facing donors and receivers of charity, and more generally the key mechanisms underlying the optimal tax treatment of charitable giving. Indeed, it turns out that assumptions regarding the warm glow of giving and the stigma of receiving charity, the strength of relative giving concerns versus the strength of relative consumption concerns, and transaction costs associated with charitable giving, respectively, are all key to understanding whether charity should be taxed or supported.

We follow the conventional theory of charitable giving in assuming that individuals experience a warm glow from donating. This is an important assumption and means that an individual $A$ derives utility from donating a certain amount to a poor individual $B$, while $A$ does not derive any utility if individual $C$ donates to $B$ or the government transfers money to $B$. By contrast, an individual motivated by pure altruism would only care about the utility of individual $B$ and not about his or her own contribution to it. The warm glow of giving assumption is supported by strong empirical evidence; see in particular Andreoni (1989, 1990).

We also follow a more recent strand of literature in assuming a prestige motive behind charitable giving, i.e., that charitable giving signals status (see, e.g., Glazer and Konrad, 1996; Harbaugh, 1998a; Cartwright and Patel, 2013). Empirical and experimental evidence demonstrates that donations are typically higher if they are observable than if they are not, and that the way in which they are reported also affects their size (e.g., Harbaugh, 1998b; Andreoni and Petrie, 2004; Alpizar et al., 2008). Furthermore, charitable giving seems to increase with the contributions made by other people (Andreoni and Petrie, 2004; Alpizar et al., 2008), suggesting that charitable giving resembles a positional good. 
In addition to the status motive behind charitable giving, a vast empirical literature shows that relative income and consumption concerns are important for individual well-being, suggesting a status motive also behind private consumption. For instance, happiness research has repeatedly found that people derive well-being from their own income or consumption relative to that of referent others, and quasi-experimental research shows that a substantial fraction of a person's utility gain from increased consumption might be due to the person's resulting increase in relative consumption (see, e.g., Johansson-Stenman et al., 2002; Solnick and Hemenway, 2005; and Carlsson et al., 2007, for evidence based on questionnaireexperimental research, and Easterlin. 2001; Blanchflower and Oswald. 2004; Ferrer-iCarbonell, 2005; and Clark and Senik, 2010, for evidence based on happiness research). This is directly relevant in the context of charitable giving, since relative consumption concerns typically influence the decisions to donate and, therefore, the optimal policy responses to charitable giving.

By analogy to the warm glow of giving, we assume that recipients of charity suffer from social stigma or shame in the sense that they derive disutility from receiving charity (for a given consumption level). While poverty in itself can also be associated with shame, as noted by Sen $(1983,1999)$, there is ample empirical evidence from sociological studies of social stigma related to receiving charity and targeted welfare benefits; see, e.g., Chase and Walker (2013) and Baumberg (2016). There is also an economics literature on the implications of social stigma. For instance, Moffitt (1983) defines welfare stigma as the corresponding lack of self-respect due to an inability to support oneself, while Besley and Coate (1992) and Kleven and Kopczuk (2011) analyze how social stigma may matter for public policy. Moreover, a robust finding in the literature on subjective well-being is that unemployment tends to imply reduced well-being, also when correcting for the income loss that unemployment gives rise to (e.g., Clark and Oswald, 1994; Blanchflower and Oswald, 2004). This is clearly at odds with the assumptions normally made in economics, since unemployment implies more leisure, but it is consistent with the idea of a stigma associated with living on welfare. While one can argue that there may be a stigma component also from favorable treatment through the tax system, we will focus on the stigma of receiving charitable donations in what follows, by assuming that potential charity recipients prefer 
redistribution through the tax system over receiving the same funds through charitable donations. $^{4}$

Several earlier studies, including Feldstein (1980), Warr (1983), Roberts (1987), Saez (2004), Diamond (2006), Blumkin and Sadka (2007), and Aronsson, Johansson-Stenman, and Wendner (2019), have examined optimal tax policy in various settings in economies where charitable giving is modelled in terms of voluntary contributions to a public good. An important task of the government is then to simultaneously decide how much of the public good it should provide directly and the extent to which it should support private contributions. Saez (2004) integrates charitable giving into a model of optimal linear taxation and characterizes the optimal subsidy (or tax) attached to voluntary contributions to the public good. Diamond (2006) extends the analysis to a model of optimal nonlinear taxation and shows that voluntary contributions to the public good by those with the highest earning ability lead to higher welfare through a relaxation of the incentive constraint.

Similar to our study, Blumkin and Sadka (2007) and Aronsson, Johansson-Stenman, and Wendner (2019) analyze status-related motives behind charitable giving, albeit in very different contexts. In the model by Blumkin and Sadka, status signaling constitutes the only motive for charitable giving. They examine the welfare effects of introducing a tax on charitable giving under an optimal linear income tax and find that the optimal tax on such giving is non-negative. Aronsson, Johansson-Stenman, and Wendner (2019), a companion paper to the present one that shares some important model assumptions, analyze the optimal tax treatment of voluntary contributions to a public good, to which the government also contributes through public revenue. That paper compares the policies decided on by a conventional welfarist government (which respects all aspects of consumer preferences and bases the social objective thereupon) with the policies chosen by different paternalist governments (which do not respect welfare effects from social comparisons and the warm glow of giving, respectively). A major finding is that welfarist and paternalist governments may choose quite similar policies despite that their motives for influencing voluntary contributions to public goods differ in fundamental ways.

The studies closest in spirit to ours are Atkinson (1976) and Kaplow (1995, 1998), in the sense that these papers also consider pure redistribution in terms of private consumption

\footnotetext{
${ }^{4}$ It is possible to interpret the stigma from receiving charity in our model as a net stigma effect compared with the stigma of receiving the same amount through the tax system.
} 
through charitable gifts. Kaplow analyzes model economies where the donor is altruistic, and concludes that the equilibrium implies under-provision of donations relative to a first-best social welfare optimum (based on a utilitarian social welfare function), since each donor will only take into account their own utility associated with the donation (regardless of whether the donation per se is motivated by altruism or warm glow) and not the utility of the receiver. ${ }^{5}$ Therefore, a Pigouvian subsidy would take the economy to the first-best optimum. Atkinson uses a similar framework to examine the conditions under which tax deductions for charitable contributions are preferable to a tax credit, and vice versa. Yet, none of these studies attempt to integrate charitable giving into a framework of optimal redistributive taxation.

Albeit based on a very different model, we follow Atkinson and Kaplow in considering pure redistribution, in terms of private consumption, through charitable donations from the rich to the poor, or more specifically in our model setup from individuals with high earning ability to individuals with low earning ability. ${ }^{6}$ This approach is arguably relevant for at least two reasons. First, most earlier studies on the tax treatment of charitable donations referred to above have focused on public goods aspects and thus paid less attention to aspects associated with redistribution. Second, it allows us to examine the interesting question of whether - and if so to what extent - the government should redistribute via the tax system, and to what extent it should support private redistribution through gifts. We assume that the government redistributes by using a nonlinear income tax, possibly combined with a tax instrument directly targeting charitable giving, and that earning ability is private information. Diamond (2006) and Aronsson, Johansson-Stenman, and Wendner (2019) also consider models with nonlinear taxation, yet they focus on contributions to public goods instead of pure redistribution. As in Diamond (2006), we find that a subsidy for charitable giving works as a mechanism to relax the self-selection constraint, although for a completely different reason: the stigma of receiving charity makes mimicking less attractive.

Our paper also contributes to a strand of literature dealing with optimal taxation in economies where people derive well-being from their relative consumption compared with referent others. A major issue in this literature has been to examine how positional concerns ought to affect the structure of marginal income taxation and/or commodity taxation, which a number

\footnotetext{
${ }^{5}$ The donor only recognizes the recipient's preferences indirectly (since the donor derives utility from the wellbeing of the recipient), whereas the social welfare function also directly reflects the preferences of the recipient.

${ }^{6}$ See Auten et al. (2002) and Clotfelter $(1992,2014)$ for extensive empirical analyses of the redistributive effects of charity.
} 
of studies have addressed based on various models and tax instruments. ${ }^{7}$ It is now well established that a negative consumption externality caused by such comparisons calls for higher marginal tax rates and more redistribution compared with conventional models of optimal taxation (where people do not care about their relative consumption). ${ }^{8}$ Yet, this literature addresses neither the consequences of positional concerns in terms of redistributive charitable giving nor the optimal tax policy implications thereof, which are major issues in the present paper.

In summary, the present paper integrates pure redistribution through charitable giving into a framework of optimal redistributive income taxation by simultaneously examining warmglow of giving, transaction costs, status concerns, and social stigma of receiving charity. This contribution is significant for at least four reasons: First, the analysis of several different motives for redistribution through charitable giving makes it possible to pin down more clearly the crucial conditions under which charitable giving should be supported or not. Second, if individuals try to signal status through both consumption and charitable giving - as the evidence presented above seems to suggest - the joint policy implications ought to be addressed simultaneously in the same framework. Indeed, our results show that relative consumption concerns directly affect the optimal policy targeted at charitable giving, which suggests that policies targeting different positional externalities may interact in important ways. Third, we offer a broad perspective on the tax policy implications of charitable giving by distinguishing between a case where the government can influence charitable giving through a direct tax instrument and one where it can not. This distinction is practically relevant: whereas many countries rely on direct tax incentives (such as various deduction schemes) to influence charitable giving, some others do not. It is therefore important to compare the optimal tax policies under a full set of tax instruments (including a direct instrument targeting the level of charitable giving) with the optimal tax policy that would follow in the absence of such an instrument. A setting where the government lacks a direct tax instrument for targeting charitable giving is also interesting more generally as it exemplifies a realistic case where the government has fewer effective tax instruments than variables it wishes to influence. This may be due to an inability of perfectly observing charitable giving

\footnotetext{
${ }^{7}$ See, e.g., Boskin and Sheshinski (1978), Layard (1980), Oswald (1983), Dupor and Liu (2003), Aronsson and Johansson-Stenman (2008, 2010), Eckerstorfer and Wendner (2013), and Kanbur and Tuomala (2013).

${ }^{8}$ A corrective tax element of similar magnitude typically follows if the government is paternalist in the sense of not respecting the consumer preference for relative consumption. Although such a government is not concerned with externality correction, it would like each individual to behave as if the preference for relative concerns were absent. In turn, this calls for a corrective tax element closely related to the positional externality; see Aronsson and Johansson-Stenman (2018).
} 
by the government, or due to political restrictions. Fourth, by using an optimal income tax model with information asymmetries, we are able to relate the tax policy implications of private redistribution through charitable giving more closely to the modern literature on optimal redistributive taxation. Thus, our approach differs from Atkinson (1976) and Kaplow (1995, 1998), who did not formally address redistribution through optimal taxation. In addition to the added realism, allowing for nonlinear taxation has the obvious advantage over more restrictive tax instruments in that the results are straightforward to interpret: tax wedges relate directly to information limitations and externalities in our model instead of to an amalgam of these motives for taxation and an arbitrary linearity restriction. In this sense, our study also complements Diamond (2006) and Aronsson, Johansson-Stenman, and Wendner (2018) by examining other aspects of charitable giving than they did.

The paper is organized as follows. Section 2 presents a baseline model where consumers differ in earning ability, which is private information, while both income and charitable giving are observable to the government. As we simplify by distinguishing between only two ability types, we also assume that high-ability individuals are the sole contributors to charity and that all low-ability individuals receive an equal share of these gifts. ${ }^{9}$ Very briefly, we show in Section 3 that charity may either be taxed or subsidized at the margin in the secondbest optimum, depending on the relative strengths of the warm glow of giving and stigma from receiving charity, respectively, and on the positional externalities caused by charitable donations. We also show that positional consumption externalities directly affect this marginal tax/subsidy if charitable giving is associated with transaction costs.

In Section 4, we relax the assumption that the government can control charitable giving through a direct instrument. This is primarily motivated by the fact that many countries, for whatever reason, simply do not use any direct tax incentives related to charitable giving. Regardless of the reasons for this (e.g., due to political or administrative arguments and restrictions), it is thus important to analyze how the absence of a direct tax instrument affects the optimal marginal income tax structure. The income taxes will then also work as indirect instruments for controlling charitable giving, which affects the marginal tax rate of the highability type. Yet, the sign of this tax rate is in general ambiguous (even if we were to assume that relative consumption concerns per se motivate a higher marginal income tax rate); we give a detailed characterization of the mechanisms underlying the optimal marginal tax rates.

\footnotetext{
${ }^{9}$ Thus, our model is an extension of Stiglitz' (1982) two-type model of optimal income taxation.
} 
In Section 5, we present extensive numerical simulations. These illustrate some of the most important theoretical results presented in Sections 3 and 4, and also quantify how the marginal tax and redistribution policies vary with key parameters of the model based on explicit functional form assumptions. Section 6 concludes the paper, and the Appendix presents the proofs and mathematical results that support the analysis in the main text.

\section{A Model with Social Comparisons and Charitable Giving}

Consider an economy comprising $N$ individuals, of whom $n^{1}$ are of a low-ability type (type 1 ) and $n^{2}$ are of a high-ability type (type 2). This distinction refers to earning ability, which we interpret to mean that high-ability individuals earn a higher before-tax wage rate than lowability individuals. Following Aronsson and Johansson-Stenman (2008), each individual of ability type $i(i=1,2)$ derives utility from their own absolute consumption, $c^{i}$, and leisure time, $z^{i}$, as well as from their own consumption relative to a reference consumption level, $\Delta c^{i}=c^{i}-\bar{c}$. The reference consumption level is given by the average consumption in the economy as follows: ${ }^{10}$

$$
\bar{c} \equiv \frac{n^{1} c^{1}+n^{2} c^{2}}{N} .
$$

Individuals also derive utility from their net charitable giving, $g^{i}$, such that each individual prefers to give rather than receive charity for a given consumption level. Those who give to charity experience a warm glow effect, whereas those who receive charity face a stigma effect. In addition to pure warm glow, donors care about their relative contribution, i.e., how much they give compared with other contributors, whereas those who receive charity analogously care about how much they receive compared with other recipients. In other words, each individual cares about $\Delta g^{i}=g^{i}-\bar{g}^{i}$, where $\bar{g}^{i}$ is the average net contribution of type $i$. Since all individuals of type $i$ are identical, it follows that $\bar{g}^{i}=g^{i}$ in equilibrium. This means that the warm-glow effect of the absolute donation is not the only motive for charitable giving; individuals also derive utility from giving more than their referent others. By a symmetrical

\footnotetext{
${ }^{10}$ The difference comparison, where each individual's relative consumption is given by the difference between the individual's own consumption and the reference consumption level, is commonly used in the literature (e.g., Galí, 1994; Akerlof, 1997; Ljungqvist and Uhlig, 2000; Bowles and Park, 2005; and Aronsson and JohanssonStenman, 2008, 2010, 2014). A quotient formulation of the relative consumption (as in Boskin and Sheshinski, 1978; Layard, 1980; Abel, 2005; and Wendner and Goulder, 2008) would give the same qualitative results in terms of policy incentives.
} 
argument, receivers of charitable donations do not only face a direct stigma effect attached to the absolute donation, but may also derive disutility by receiving more than others.

We will solely focus on the case where, in equilibrium, high-ability individuals contribute to charity and low-ability individuals receive charitable donations. We also assume that there is a transaction cost associated with charity such that the total amount received by low-ability individuals is less than the amount spent on charitable giving by high-ability individuals (although we will also consider the limit case of zero transaction costs). For the low-ability individuals to receive $g^{2}$ dollars, the high-ability individuals will have to spend $g^{2}+\mu\left(g^{2}\right)$ dollars, where $\mu\left(g^{2}\right) \geq 0$ is the transaction cost of giving to charity. ${ }^{11}$ The marginal resource cost is assumed to be non-negative, $\mu_{g}\left(g^{2}\right)=\partial \mu\left(g^{2}\right) / \partial g^{2} \geq 0$. A natural interpretation is that a higher amount donated typically requires the household to collect more information on presumptive charities.

\subsection{Preferences and Behavior}

We assume that the utility function facing any individual of ability-type $i$ takes the following form:

$$
U^{i}=v^{i}\left(c^{i}, z^{i}, g^{i}, \Delta c^{i}, \Delta g^{i}\right)=u^{i}\left(c^{i}, z^{i}, g^{i}, \bar{c}, \bar{g}^{i}\right) .
$$

The function $v^{i}(\cdot)$ defines utility as a function of the individual's own consumption, leisure, and net charitable giving, respectively, as well as of the individual's relative consumption and relative net charitable giving. $v^{i}(\cdot)$ is strictly quasi-concave, increasing in $c^{i}$ and $z^{i}$, and nondecreasing in $g^{i}, \Delta c^{i}$, and $\Delta g^{i}$. The function $u^{i}(\cdot)$ is a reduced form that helps shorten some of the notation. Equation (2) implies the following relationships between $u^{i}(\cdot)$ and $v^{i}(\cdot)$ : $u_{c}^{i}=v_{c}^{i}+v_{\Delta c}^{i}>0, u_{z}^{i}=v_{z}^{i}>0, u_{\bar{c}}^{i}=-v_{\Delta c}^{i} \leq 0, u_{g}^{i}=v_{g}^{i}+v_{\Delta g}^{i} \geq 0$, and $u_{\bar{g}^{i}}^{i}=-v_{\Delta g}^{i} \leq 0$, where subscripts denote partial derivatives.

Let us also consider a less general, leisure separable version of the utility function written as follows (if based on the reduced form utility formulation in equation [2]):

$$
U^{i}=V^{i}\left(h\left(c^{i}, g^{i}, \bar{c}, \bar{g}^{i}\right), z^{i}\right) .
$$

\footnotetext{
${ }^{11}$ Since many options are available for charitable donations, this assumption is clearly reasonable. In addition, such a cost is also interesting from the perspective of policy incentives, as it contributes to intertwine the policies used to correct for positional consumption externalities and positional gifts externalities.
} 
The leisure separable utility function in equation (3) implies that the marginal rates of substitution between $c^{i}, g^{i}, \bar{c}$, and $\bar{g}^{i}$ are all independent of leisure. Note that while the utility function may still vary between types, the sub-utility function $h$ is the same among types. Leisure separable utility functions play an important role in the literature on optimal taxation. It is thus useful to compare the results derived from the general utility function in equation (2) with those that follow from the leisure separable utility function.

In our two-type setting, high-ability individuals contribute to charity and low-ability individuals receive charitable donations. ${ }^{12}$ Note that the charitable donation received by each low-ability individual is given by $g^{1}=-n^{2} g^{2} / n^{1}$. The individual budget constraint facing each type can then be written as

$$
\begin{aligned}
& w^{1} l^{1}+g^{2} n^{2} / n^{1}-c^{1}-T\left(w^{1} l^{1}, 0\right)=0, \\
& w^{2} l^{2}-c^{2}-g^{2}-\mu\left(g^{2}\right)-T\left(w^{2} l^{2}, g^{2}\right)=0,
\end{aligned}
$$

where $l^{i}$ denotes work hours, defined as a time endowment (normalized to unity) less the time spent on leisure, i.e., $l^{i}=1-z^{i}$, and $w^{i}$ denotes the hourly before-tax wage rate. The function $T\left(w^{i} l^{i}, g^{i}\right)$ is a general tax function through which the tax payment depends on both income and charitable giving. Thus, we assume that there is no tax on receiving charity, such that $T\left(w^{1} l^{1}, g^{1}\right)=T\left(w^{1} l^{1}, 0\right)$.

An individual chooses consumption and labor supply, as well as giving if being a high-ability type, to maximize utility given by equation (2) subject to the budget constraint in equations (4a) and (4b), while treating the reference consumption, $\bar{c}$, reference giving, $\bar{g}^{i}$, wage rate per unit of labor, $w^{i}$, and the parameters of the tax system (including the structure of marginal tax rates) as exogenous. In addition to equations (4a) and (4b), an interior solution satisfies the following first-order conditions for work hours:

$$
M R S_{z, c}^{i} \equiv \frac{u_{z}^{i}}{u_{c}^{i}}=\frac{v_{z}^{i}}{v_{c}^{i}+v_{\Delta c}^{i}}=w^{i}\left(1-T_{w l}^{i}\right), i=1,2,
$$

and the following first-order condition for charitable giving:

\footnotetext{
${ }^{12}$ Instead of assuming that all low-ability individuals receive charitable donations, an alternative would be to assume that they differ in their preferences for charitable donations (such as in the stigma perceived), meaning that only some of them will accept donations in the end. Yet another alternative would be to assume that charitable donations are allocated by lottery among the low-ability individuals. Both of these assumptions would increase the analytical complexity of the model, while the main mechanisms driving the results would be the same as below.
} 


$$
M R S_{g, c}^{2} \equiv \frac{u_{g}^{2}}{u_{c}^{2}}=\frac{v_{g}^{2}+v_{\Delta g}^{2}}{v_{c}^{2}+v_{\Delta c}^{2}}=1+T_{g}^{2}+\mu_{g} .
$$

$T_{w l}^{i}$ is the marginal income tax rate facing each individual of ability-type $i$, and $T_{g}^{2}$ is the marginal tax (if positive) or subsidy (if negative) on charitable giving faced by high-ability individuals.

Turning to the production side of the economy, we follow much earlier literature in assuming for both ability types a linear technology with labor of as the only input, and that the labor market is competitive. Consequently, the marginal labor productivities, as measured by the before-tax wage rates, are fixed. ${ }^{13}$

\subsection{The Problem of the Government}

We assume that the government is able to observe income and charitable giving at the individual level, while earning ability (as measured by the before-tax wage rate) is private information. This means that the government can (i) tax income according to a nonlinear schedule and (ii) directly tax or subsidize charitable giving. In Section 4, we consider a more restrictive case where the government lacks a direct instrument for taxing or subsidizing charitable giving, although it can still implement a nonlinear income tax. We also assume that the government wants to redistribute from the high-ability to the low-ability type. This means that we must add a self-selection constraint, such that high-ability individuals (weakly) prefer the allocation intended for their type over the allocation intended for the low-ability type. By using $g^{1}=-n^{2} g^{2} / n^{1}$ and $\Delta g^{1}=g^{1}-\bar{g}^{1}=-n^{2}\left(g^{2}-\bar{g}^{2}\right) / n^{1}=-n^{2} \Delta g^{2} / n^{1}$, the utility function of a potential mimicker, denoted by a hat, ${ }^{14}$ is given by

$$
\begin{aligned}
\hat{U}^{2} & =\hat{v}^{2}\left(c^{1}, 1-\phi l^{1},-n^{2} g^{2} / n^{1}, \Delta c^{1},-n^{2} \Delta g^{2} / n^{1}\right), \\
& =\hat{u}^{2}\left(c^{1}, 1-\phi l^{1},-n^{2} g^{2} / n^{1}, \bar{c},-n^{2} \bar{g}^{2} / n^{1}\right)
\end{aligned}
$$

where $\phi \equiv w_{1} / w_{2}$ denotes the relative wage rate and $\phi l^{1}$ represents the mimicker's labor supply. The potential mimicker is a high-ability individual who chooses to earn the same income as the low-ability type. Furthermore, since charitable giving is observable, a potential mimicker will receive as much charity as the true low-ability individuals. Consequently, the mimicker will be subject to the same stigma and relative stigma effects. Thus, if expressed in terms of the function $v^{2}(\cdot)$ in equation (2), the self-selection constraint can be written as

\footnotetext{
${ }^{13}$ This property simplifies the calculations; it is not important for the optimal tax treatment of charitable giving.

${ }^{14}$ Note that the mimicker and the true high-ability type share a common utility function. The hat symbol just allows us to separate them in a simple way.
} 


$$
v^{2}\left(c^{2}, z^{2}, g^{2}, \Delta c^{2}, \Delta g^{2}\right) \geq \hat{v}^{2}\left(c^{1}, 1-\phi l^{1},-n^{2} g^{2} / n^{1}, \Delta \mathrm{c}^{1},-n^{2} \Delta g^{2} / n^{1}\right) .
$$

The economy's resource constraint is given by

$$
\sum_{i=1}^{2} n^{i} w^{i} l=\sum_{i=1}^{2} n^{i} c^{i}+n^{2} \mu\left(g^{2}\right) .
$$

Equation (8) means that output is used for private consumption and the transaction cost associated with charitable giving. The direct transfer of charitable giving washes out of the resource constraint, as the donations are just a flow of resources from the high- to the lowability type.

We consider the general social objective of reaching a Pareto-efficient allocation by maximizing the utility of the low-ability type subject to a minimum utility level for the highability type and to the self-selection and resource constraints in equations (7) and (8). Furthermore, the government internalizes the positional externalities by taking into account that $\bar{c}$ and $\bar{g}^{2}$ are endogenous. The socially optimal resource allocation solves the following problem:

$$
\begin{aligned}
\underset{c^{1}, c^{2}, l^{l}, l^{2}, g^{2}}{\operatorname{Lax}} & =v^{1}\left(c^{1}, z^{1},-g^{2} n^{2} / n^{1}, \Delta c^{1},-n^{2} \Delta g^{2} / n^{1}\right) \\
& +\delta\left[v^{2}\left(c^{2}, z^{2}, g^{2}, \Delta c^{2}, \Delta g^{2}\right)-\bar{U}^{2}\right]+\gamma\left[\sum_{i=1}^{2} n^{i} w^{i} l^{i}-\sum_{i=1}^{2} n^{i} c^{i}-n^{2} \mu\left(g^{2}\right)\right], \\
& +\lambda\left[v^{2}\left(c^{2}, z^{2}, g^{2}, \Delta c^{2}, \Delta g^{2}\right)-\hat{v}^{2}\left(c^{1}, 1-\phi l^{1},-g^{2} n^{2} / n^{1}, \Delta c^{1},-n^{2} \Delta g^{2} / n^{1}\right)\right]
\end{aligned}
$$

subject to $\bar{c}=\left(n^{1} c^{1}+n^{2} c^{2}\right) / N$ and $\bar{g}^{2}=g^{2}$. The parameter $\bar{U}^{2}$ represents a fixed minimum utility level for the high-ability type, while the Lagrange multipliers refer to the minimum utility restriction $(\delta)$, the resource constraint $(\gamma)$, and the self-selection constraint $(\lambda)$. The social first-order conditions for an interior solution are as follows:

$$
\begin{gathered}
L_{c^{1}}=v_{c}^{1}+v_{\Delta c}^{1}-\lambda\left(\hat{v}_{c}^{2}+\hat{v}_{\Delta c}^{2}\right)-\gamma n^{1}+\frac{n^{1}}{N} L_{\bar{c}}=0, \\
L_{c^{2}}=(\delta+\lambda)\left(v_{c}^{2}+v_{\Delta c}^{2}\right)-\gamma n^{2}+\frac{n^{2}}{N} L_{\bar{c}}=0, \\
L_{l^{1}}=-v_{z}^{1}+\lambda \phi \hat{v}_{z}^{2}+\gamma n^{1} w^{1}=0, \\
L_{l^{2}}=-(\delta+\lambda) v_{z}^{2}+\gamma n^{2} w^{2}=0, \\
L_{g^{2}}=(\delta+\lambda) v_{g}^{2}-v_{g}^{1} n^{2} / n^{1}+\lambda \hat{v}_{g}^{2} n^{2} / n^{1}-\gamma n^{2} \mu_{g}\left(g^{2}\right)=0 .
\end{gathered}
$$

In equations (10) and (11), $L_{\bar{c}}$ denotes the partial welfare effect of increased reference consumption, $\bar{c}$, given by

$$
L_{c}=-v_{\Delta c}^{1}-(\delta+\lambda) v_{\Delta c}^{2}+\lambda \hat{v}_{\Delta c}^{2} .
$$


The right-hand side of equation (15) is ambiguous in sign, since an increase in $\bar{c}$ reduces the utility for both the true ability types (which contributes to lower welfare) and the mimicker (which contributes to higher welfare).

\section{Optimal Taxation}

In this section, we derive and present the optimal marginal tax rates by comparing the social first-order conditions in equations (10)-(14) with the private first-order conditions given in equations (5) and (6). To simplify the presentation of the results, we start by considering a simplified version of the model where the transaction cost of charitable giving is zero. In this case, the marginal tax/subsidy attached to charitable contribution will be shown to only reflect the warm glow of giving and stigma of receiving charity as well as the positional gift externality; it does not directly depend on the positional consumption externality.

As will be shown, the policy rules for marginal taxation (of income and charitable giving) depend on the extent to which the relative consumption and relative charitable giving, respectively, affect individual well-being. It is, therefore, instructive to introduce the following degrees of consumption positionality, $\alpha^{i}$, and gifts positionality, $\beta^{i}$ :

$$
\begin{gathered}
\alpha^{i} \equiv \frac{v_{\Delta c}^{i}}{v_{c}^{i}+v_{\Delta c}^{i}}, \\
\beta^{i} \equiv \frac{v_{\Delta g}^{i}}{v_{g}^{i}+v_{\Delta g}^{i}},
\end{gathered}
$$

where $0 \leq \alpha^{i}, \beta^{i}<1$ by the assumptions made earlier. The degree of consumption positionality measures the share of the marginal utility of consumption arising from an increase in relative consumption (e.g., Johansson-Stenman et al., 2002).

Similarly, the degree of gifts positionality is measured as the share of the marginal utility of charitable giving arising from an increase in relative charitable giving. Thus, $\beta^{2}$ reflects the share of the utility gain for a high-ability individual of an additional dollar spent on charitable giving that is attributable to increased relative giving (compared with other high-ability individuals). Correspondingly, low-ability individuals who receive charity will experience a utility decrease (for a given consumption level) for two reasons: due to an increased absolute amount of charity received and due to an increased amount of charity received relative to 
what others receive. The parameter $\beta^{1}$ reflects the share of the utility decrease attributable to the increased relative charity received.

Finally, we also define the average degree of consumption positionality, $\bar{\alpha} \equiv\left(\alpha^{1} n^{1}+\alpha^{2} n^{2}\right) / N$, which reflects the marginal positional consumption externality per unit of consumption, and an indicator of the difference in the degree of consumption positionality between the mimicker and the low-ability type, $\alpha^{d} \equiv\left(\hat{\alpha}^{2}-\alpha^{1}\right) \lambda \hat{u}_{c}^{2} /(\gamma N)$. Quasiexperimental research estimates $\bar{\alpha}$ to be in the $0.2-0.5$ range (see, e.g., Johansson-Stenman et al., 2002; Clark and Senik, 2005; Carlsson et al., 2007; and the overview given in Wendner and Goulder, 2008). Despite the empirical evidence for status signaling and/or positional concerns with respect to charitable giving mentioned in the introduction, we are not aware of any direct estimate of the degree of gifts positionality.

\subsection{Optimal Marginal Income Tax Rates}

The policy rules for marginal income taxation take the same form irrespective of whether charitable giving is costly. It is straightforward to show (see the Appendix) that the optimal marginal income tax rates are given as follows (for $i=1,2$ ):

$$
T_{w l}^{i}\left(w^{i} l^{i}, g^{i}\right)=\tau^{i}+\left[1-\tau^{i}\right] \bar{\alpha}-\left[1-\tau^{i}\right][1-\bar{\alpha}] \frac{\alpha^{d}}{1-\alpha^{d}} .
$$

In the leisure separable case, i.e., given preferences according to equation ( $3 b), \hat{\alpha}^{2}=\alpha^{1}$ such that $\alpha^{d}=0$, and equation (18a) reduces to

$$
T_{w l}^{i}\left(w^{i} l^{i}, g^{i}\right)=\tau^{i}+\left[1-\tau^{i}\right] \bar{\alpha} .
$$

The variable $\tau^{i}$ is a short notation for the marginal income tax formula faced by type $i$ in the standard two-type model, in which there are no concerns about either relative consumption or charity. Note that the marginal income tax rates in (18a) are identical to the ones derived by Aronsson and Johansson-Stenman (2008) in a model without charitable giving. The reason equation (18a) applies here as well is that the government can control charitable giving through a direct tax instrument, meaning that charitable giving will not change the policy rule for marginal income taxation. As we show in Section 4, without a direct tax instrument for influencing the level of charitable giving, equation (18a) would no longer apply.

Briefly, the policy rule for marginal income taxation can be decomposed into three components. The first, $\tau^{i}$, denotes the policy rule for marginal taxation that would be 
implemented in the absence of any positional consumption externality. This component is typically positive for the low-ability types and serves to relax the self-selection constraint by exploiting that the low-ability type attaches a higher marginal value to leisure than a potential mimicker does, while it is zero for the high-ability type under the assumption of a fixed relative wage rate. ${ }^{15}$ The second component on the right-hand side of equation (18a) represents a corrective tax element and depends on the average degree of positionality, $\bar{\alpha}$, which is a measure of the positional consumption externality per unit of consumption. Note that this effect is scaled down by $1-\tau^{1}<1$ for the low-ability type, since the fraction of an additional unit of income already taxed away for other reasons does not give rise to any externalities. Finally, the third component reflects how the government exploits differences in the degree of positionality between the mimicker and the (mimicked) low-ability type to relax the self-selection constraint. If a potential mimicker is more positional than the low-ability type ( $\left.\alpha^{d}>0\right)$, the government can relax the self-selection constraint through a policy-induced increase in the level of reference consumption, $\bar{c}$, which, in turn, constitutes an incentive to implement a lower marginal income tax rate than otherwise. By analogy, if the low-ability type is more positional than a potential mimicker $\left(\alpha^{d}<0\right)$, there is a corresponding motive to increase the marginal income tax rate beyond the level represented by the sum of the first two terms. These mechanisms are discussed at length in Aronsson and Johansson-Stenman (2008) and will not be discussed further here.

\subsection{Optimal Marginal Tax/Subsidy Rates for Charity without Transaction Costs}

We will now turn to the marginal tax/subsidy on charitable giving. To simplify the presentation and interpretation, we begin with the case most commonly analyzed in the literature, where there are no transaction costs of giving, i.e., where $\mu_{g}\left(g^{2}\right)=0$ for $g^{2}$. Immediately from equation (14), we obtain the following social first-order condition for charitable giving:

$$
(\delta+\lambda) v_{g}^{2} n^{1} / n^{2}=v_{g}^{1}-\lambda \hat{v}_{g}^{2}>0 .
$$

Equation (19) implies that the social marginal utility of charitable giving (the left-hand side) is equal to a "net marginal stigma cost," i.e., the social marginal stigma cost imposed on the low-ability type, $v_{g}^{1}>0$, adjusted for the social marginal benefit of imposing stigma on the mimicker, $\lambda \hat{v}_{g}^{2}>0$, which contributes to relax the self-selection constraint. It is worth noting

\footnotetext{
${ }^{15}$ See, e.g., Stiglitz (1982).
} 
that the social marginal benefits and costs of charitable giving are measured with the indicator of relative giving, $\Delta g^{2}$, held constant, since the externalities that relative concerns about charity give rise to are internalized in the social optimum.

In the absence of any stigma effect, in which case $v_{g}^{1}-\lambda \hat{v}_{g}^{2}=0$, an interior social optimum (if it exists) would imply $v_{g}^{2}=0$. If being a receiver of charity is associated with stigma, and if the self-selection constraint is not binding $(\lambda=0)$, the first-order condition (19) means $v_{g}^{2}>0$, i.e., a lower level of charitable giving due to the marginal utility cost of stigma for the low-ability type. This stigma effect is intuitive. Yet, if the self-selection constraint is binding $(>0)$, the stigma effect on the mimicker relaxes the self-selection constraint. As a consequence, more charitable giving is optimal (i.e., $v_{g}^{2}$ is lowered by the term $\lambda \hat{v}_{g}^{2}$ ).

By noting that equation (19) requires $v_{g}^{1}-\lambda \hat{v}_{g}^{2}>0$, the marginal tax/subsidy on charitable giving is characterized as follows:

Proposition 1. Without transaction costs, the optimal marginal tax/subsidy rate for charitable giving can be written as

$$
T_{g}^{2}=\frac{1}{\left(1-\beta^{2}\right)} \frac{v_{g}^{1}-\lambda \hat{v}_{g}^{2}}{\Psi}-1
$$

where $\Psi=v_{c}^{1}+v_{\Delta c}^{1}-\lambda\left(\hat{v}_{c}^{2}+\hat{v}_{\Delta c}^{2}\right)=v_{c}^{1} /\left(1-\alpha^{1}\right)-\lambda \hat{v}_{c}^{2} /\left(1-\hat{\alpha}^{2}\right)$. In the leisure separable case where the utility function takes the form of equation (3), equation (20) simplifies to read

$$
T_{g}^{2}=\frac{1-\alpha^{1}}{1-\beta^{2}} \frac{v_{g}^{1}}{v_{c}^{1}}-1
$$

Proof: See the Appendix.

To interpret Proposition 1, we begin with the leisure separable case and by noting that the policy rule in equation (21) coincides with the policy rule that would apply under first-best conditions where the self-selection constraint does not bind (i.e., if $\lambda=0$ ). ${ }^{16}$ The ratio $v_{g}^{1} / v_{c}^{1}$ is

\footnotetext{
${ }^{16}$ Under leisure separability (as formalized in equation [3]), there is no distributional benefit of deviating from the first-best policy rule in equation (21). In other words, efficiency concerns alone govern the marginal tax/subsidy on charitable giving, whereas the marginal income tax policy reflects both the incentive to relax the
} 
a low-ability individual's marginal willingness to pay to avoid the stigma from receiving charitable donations, measured with the relative charitable benefit $\left(\Delta g^{1}\right)$ and the relative consumption $\left(\Delta c^{1}\right)$ held constant. As the government recognizes that relative comparisons are pure waste from society's point of view, $v_{g}^{1} / v_{c}^{1}$ is interpretable as a measure of social marginal willingness to pay to avoid stigma. If the relative concerns were absent, such that $\alpha^{1}=\beta^{2}=0$, this marginal willingness to pay would be the sole determinant of the optimal marginal tax/subsidy on charitable giving, i.e., equation (21) would read $T_{g}^{2}=v_{g}^{1} / v_{c}^{1}-1$. In the extreme case where the stigma effect is so large that individuals of the low-ability type are indifferent between accepting and not accepting additional charity, then $v_{g}^{1} / v_{c}^{1}=1$ and $T_{g}^{2}=0$, i.e., charity should be neither taxed nor subsidized at the margin. In the other extreme case of no stigma effect, such that $v_{g}^{1}=0$, it follows that $T_{g}^{2}=-1$, i.e., a marginal subsidy rate of 100 percent. ${ }^{17} \mathrm{In}$ all cases in between these extremes, i.e., where $0<v_{g}^{1} / v_{c}^{1}<1$, it follows that $-1<T_{g}^{2}<0$, implying that charity should be subsidized, although at a rate of less than 100 percent.

The key here is that charitable giving leads to higher utility for the donor (high-ability type) without influencing the economy's resource constraint. Moreover, we know the size of this utility increase for the donor: since high-ability individuals give for free, and since they maximize their utility by doing so, we know that the marginal benefit of giving an additional dollar equals the marginal benefit of consuming it. Thus, if there were no stigma effect, there would be an external benefit that is equally large as the donation itself, implying an optimal subsidy rate of 100 percent. It is interesting to compare this finding with the results of Kaplow (1995), who in his equation (5) derived an expression for the optimal subsidy rate in the absence of any social stigma for the receivers. He assumed a utilitarian social welfare function and that the subsidy is financed by a lump-sum tax. The result of Kaplow is still not a $100 \%$ subsidy, however, other than in a special case. This may seem puzzling, since our more general Pareto efficiency objective implicitly encompasses all Paretian social welfare functions, including Kaplow's utilitarian one. Yet, it is straightforward to show that this discrepancy disappears if one adds an optimal redistributive lump-sum tax in Kaplow's model, thus implying a subsidy rate of 100 percent in his extended model.

self-selection constraint (which opens up for more redistribution) and the correction for the positional consumption externality. That the first-best policy rule for the tax on charitable giving carries over to the leisure separable case under optimal income taxation is analogous to results derived for commodity taxation by Atkinson and Stiglitz (1976) and public good provision by Boadway and Keen (1993).

${ }^{17}$ According to equation (19), to arrive at this extreme (yet interior) solution, $v_{g}^{2}$ must approach zero when the gift reaches a certain level. 
Yet, the larger the stigma effect, the lower the external benefit and consequently the lower the marginal subsidy. In other words, the sole reason for the subsidy is the warm glow of giving. Without it, there would only be a social cost of charitable giving due to the stigma effect (the transfer of consumption possibilities from high-ability to low-ability individuals does not give rise to any social benefit, since the government can redistribute income without costs if the self-selection constraint does not bind). We will return to the warm glow issue below.

The multiplier $\left(1-\alpha^{1}\right) /\left(1-\beta^{2}\right)$ in equation (21) may either scale up or scale down the marginal subsidy (or may even turn it into a marginal tax) depending on whether the lowability type's degree of consumption positionality exceeds or falls short of the positional gift externality that each high-ability individual imposes on other people of the same type through charitable contributions (measured by $\beta^{2}$ ). An increase in $\alpha^{1}$ increases the marginal subsidy for charitable giving, ceteris paribus, as it means an even greater tendency for low-ability individuals to overestimate the marginal utility of consumption; thus, $v_{g}^{1} / v_{c}^{1}$ overestimates each low-ability individual's marginal willingness to pay for avoiding stigma, and the factor $1-\alpha^{1}$ corrects for this discrepancy. ${ }^{18}$ Similarly, an increase in $\beta^{2}$ reduces the marginal subsidy (or increases the marginal tax) on charitable giving. ${ }^{19}$ The intuition is that $\beta^{2}$ represents the fraction of type 2 individuals' marginal utility of charitable giving that is social waste, due to that their concerns about relative contribution lead to an externality, meaning that only $1-\beta^{2}$ of an additional dollar contributed gives rise to warm glow. The condition for when charity should be taxed, rather than subsidized, then follows from equation (21):

$$
T_{g}^{2}>(<) 0 \text { iff } v_{g}^{1}>(<) \frac{1-\beta^{2}}{1-\alpha^{1}} v_{c}^{1} .
$$

Let us return to the general policy rule in equation (20a), which is based on the assumptions that the self-selection constraint binds $(\lambda>0)$ and that leisure is not in general separable in terms of the utility function. Compared with equation (21), the most important implication is that the government has an incentive to relax the self-selection constraint by exploiting that charitable benefits lead to disutility for the mimicker due to the stigma effect. ${ }^{20}$ However,

\footnotetext{
${ }^{18}$ Note that this component has nothing to do with correction for positional consumption externalities, which is accomplished through marginal income taxation. Instead, this component arises because relative consumption concerns lead to a discrepancy between the private and social marginal utility of consumption.

${ }^{19}$ This result resembles the finding of Blumkin and Sadka (2007a), although their model differs from ours in several important ways.

${ }^{20}$ Diamond (2006) also finds that subsidized contributions may relax the self-selection constraint, although for reasons other than those discussed here. In his model, individuals may voluntarily contribute to a public good,
} 
consider first an interesting special case of equation (20a), namely the case of no stigma effects, which reproduces one of the extreme results discussed in the context of equation (21):

Corollary 1. Without transaction costs, and in the absence of any stigma effects, the optimal marginal tax/subsidy rate for charitable giving can be written as

$$
T_{g}^{2}=-1 \text {, }
$$

This result follows immediately from equation (20) if $\lambda \hat{v}_{g}^{2}=v_{g}^{1}=0$. The intuition is again that charitable giving leads to higher utility for the donors without influencing the economy's resource constraint, while the receivers are indifferent between public and private redistribution. In the opposite extreme case where there is no warm glow of giving but a negative stigma effect of receiving donations, it follows from equation (19) that $v_{g}^{1}-\lambda \hat{v}_{g}^{2}=0$, i.e., an interior solution for charitable giving (if it exists) requires that the net marginal stigma cost is zero. To accomplish this, a 100 percent marginal subsidy rate is required here as well, although for a different reason. ${ }^{21}$ In the more interesting scenario with both warm glow and stigma effects, the optimal second-best policy is typically to subsidize charitable giving at a marginal rate of less than 100 percent or, if the net marginal stigma cost is large enough, tax charitable giving at the margin.

By comparing equations (18a) and (20a), we can see that relative concerns affect the policy rule for marginal income taxation in a different way compared with the policy rule for marginal taxation/subsidization of charitable giving. While relative consumption concerns give rise to an externality-correcting motive for income taxation, which shows up as a direct effect in the policy rules for marginal income taxation, there is no such direct externalitycorrecting charity tax in the absence of warm-glow and stigma effects. In our model, where all contributors to charity are identical, the only effect of the positional gift externality is to weaken (strengthen) the already existing incentive to subsidize (tax) charitable giving at the margin due to warm glow and stigma.

and the utility gain of a subsidy on voluntary contributions by the highest income-earners leads to a relaxation of the self-selection constraint (as it makes it less attractive for them to become mimickers).

${ }^{21}$ At this marginal rate, and in the absence of a warm glow, the high-ability type would be indifferent between charitable giving and private consumption (suggesting that the subsidy rate must exceed 100 percent for inframarginal units to induce the desired level of gifts). 
To see the intuition behind the tax treatment of positional gift externalities more clearly, consider the simplified case where there is neither an absolute warm-glow effect of giving nor an absolute stigma effect of receiving charitable donations, but where high-ability individuals still care about relative giving and low-ability ones care about relative stigma. It would then follow that $u_{g}^{i}=v_{\Delta g}^{i}=-u_{\bar{g}}^{i}$ and $u_{\bar{g}}^{i}=-v_{\Delta g}^{i}<0$ for $i=1,2$. As a consequence, the social firstorder condition for charitable giving (equation [19]) would be redundant; in fact, it would always be satisfied since $v_{g}^{1}=0, v_{g}^{2}=0$, and $\hat{v}_{g}^{2}=0$ irrespective of the level of $g^{2}$. Intuitively, if there is neither a warm glow motive to support charitable giving, nor a stigma motive to counteract it, there are no such welfare effects on which to base public policy either. This illustrates the importance of warm-glow and stigma effects for the rationale behind taxes/subsidies on charitable giving.

\subsection{Optimal Marginal Tax/Subsidy Rates for Charity with Transaction Costs}

Let us now turn to the general and more realistic version of the model set out above with transaction costs of charitable giving. Proceeding in the same way as before, we derive the following analogue to equation (19) with transaction costs:

$$
(\delta+\lambda) v_{g}^{2}=\gamma n^{2} \mu_{g}\left(g^{2}\right)+n^{2}\left(v_{g}^{1}-\lambda \hat{v}_{g}^{2}\right) / n^{1}>0 .
$$

Equation (22) thus shows that the social marginal utility of charitable giving by the highability type, $(\delta+\lambda) v_{g}^{2}$, balances the marginal transaction cost as given by $\gamma n^{2} \mu_{g}\left(g^{2}\right)$ plus the net marginal stigma cost, $\left(v_{g}^{1}-\lambda \hat{v}_{g}^{2}\right)$. According to equation (22), in the presence of a marginal cost of giving, the optimal level of giving should be reduced compared with a situation where this marginal cost is nil (as in equation [19]). We can now derive:

Proposition 2. With a positive marginal transaction cost of charitable giving, the optimal marginal tax/subsidy rate for charitable giving is by

$$
T_{g}^{2}=\frac{1}{\left(1-\beta^{2}\right)} \frac{v_{g}^{1}-\lambda \hat{v}_{g}^{2}}{\Psi}+\left[\frac{1-\bar{\alpha}}{\left(1-\alpha^{d}\right)\left(1-\beta^{2}\right)}-1\right] \mu_{g}\left(g^{2}\right)-1,
$$

In addition to the effects of charitable giving identified in Proposition 1, the positive marginal cost of charitable giving affects the optimal marginal tax/subsidy rate in the following ways:

(i) If $\frac{1-\bar{\alpha}}{\left(1-\alpha^{d}\right)\left(1-\beta^{2}\right)}-1>0$, a higher marginal transaction cost reduces the optimal marginal subsidy (increases the optimal marginal tax) on charitable giving, and 
(ii) if $\frac{1-\bar{\alpha}}{\left(1-\alpha^{d}\right)\left(1-\beta^{2}\right)}-1<0$, a higher marginal transaction cost increases the optimal marginal subsidy (reduces the optimal marginal tax) on charitable giving, ceteris paribus.

(iii) In the leisure separable case, equation (23) simplifies to

$$
T_{g}^{2}=\frac{1-\alpha^{1}}{1-\beta^{2}} \frac{v_{g}^{1}}{v_{c}^{1}}+\frac{\beta^{2}-\bar{\alpha}}{1-\beta^{2}} \mu_{g}\left(g^{2}\right)-1
$$

Proof: See the Appendix.

The first term on the right-hand side of equation (23a) is equivalent to its counterpart in equation (20), which we discussed at some length above, whereas the second term is novel and refers to the marginal transaction cost attached to charitable giving. In turn, this marginal transaction cost affects the optimal marginal subsidy/tax via two distinct mechanisms. First, since charitable giving necessitates resource use, and in order to attain a given optimal allocation, the marginal subsidy must be larger or the tax lower (in absolute terms) than without the transaction cost. This is captured by the second component in square brackets.

Second, the marginal transaction cost also affects the marginal tax (subsidy) on charitable giving via the relative concerns about both consumption and giving, as expressed by the multiplier $(1-\bar{\alpha}) /\left[\left(1-\alpha^{d}\right)\left(1-\beta^{2}\right)\right]$. As a consequence, by introducing a cost of giving, the optimal marginal subsidy/tax attached to charitable contributions will be adjusted in response to positional consumption externalities, which was not the case when this cost was nil (see Proposition 1). This is seen from the appearance of the average degree of consumption positionality, $\bar{\alpha}$, which is a measure of the marginal positional consumption externality per unit of consumption (recall that the relative consumption concerns are driven by mean-value comparisons). The average degree of positionality ${ }^{-}$in the numerator of the multiplier, $\left(1^{-}\right)$, contributes to increase the marginal subsidy (or decrease the marginal tax) on charitable giving, ceteris paribus. The intuition is that resources are lost in the process of charitable contributions. Therefore, a higher marginal subsidy or lower marginal tax shifts the households' expenditure away from consumption and thus counteracts the positional consumption externality. The denominator $\left[\left(1-\alpha^{d}\right)\left(1-\beta^{2}\right)\right]$ either reinforces $\left(\alpha^{d}<0\right)$ or counteracts $\left(\alpha^{d}>0\right)$ this effect depending on whether a potential mimicker is more or less positional in terms of consumption than the low-ability type. If the low-ability type is more positional than the mimicker $\left(\alpha^{d}<0\right)$, then decreased consumption contributes to relax the 
self-selection constraint and thus reinforces the social benefit of a decrease in the positional consumption externality. Instead, if the mimicker is more positional than the low-ability type $\left(\alpha^{d}>0\right)$, increased consumption contributes to a relaxation of the self-selection constraint. Finally, the higher the high-ability individuals' degree of positionality in charitable giving, $\beta^{2}$, the lower the marginal subsidy (the higher the marginal tax) on charitable giving, as the government realizes that relative giving is pure waste.

The components in square brackets in equation (23a) can be understood in terms of a discrepancy between the private and social marginal transaction cost of charitable giving, where the discrepancy depends on the externalities that relative concerns about consumption and donations give rise to. This discrepancy is relevant since the transaction cost means that charitable contributions will reduce the total resources available for private consumption, ceteris paribus. Consider first the special case where $\alpha^{d}=0$, i.e., where the mimicker and the low-ability type are equally consumption positional, in which case an increase in $\mu_{g}\left(g^{2}\right)$ contributes to increase (decrease) the right-hand side of equation (22) if $\beta^{2}>(<) \bar{\alpha}$. This means that the larger the positional gift externality compared with the positional consumption externality, the more the marginal transaction cost of charitable giving will contribute to reduce the marginal subsidy (or increase the marginal tax) on charitable giving. The intuition is that the private marginal transaction cost underestimates its social counterpart if $\beta^{2}>\bar{\alpha}$, which the lower marginal subsidy or higher marginal tax serves to adjust for. ${ }^{22}$ An analogous interpretation in terms of increased marginal subsidies (or lower marginal taxation) of charitable giving follows when $\beta^{2}<\bar{\alpha}$.

By relaxing the assumption that $\alpha^{d}=0$, we can also see that the more consumption positional the mimicker is relative to the low-ability type, i.e., the larger the $\alpha^{d}$, the more $\mu_{g}\left(g^{2}\right)$ will underestimate the social marginal transaction cost of charitable giving. The intuition is that the government may in this case relax the self-selection constraint by a policy-induced increase in private consumption, meaning that increased charitable giving is associated with an additional cost for that particular reason. By analogy, if the low-ability type is more consumption positional than the mimicker, such that $\alpha^{d}<0$, increased charitable giving has

\footnotetext{
${ }^{22}$ This result is further emphasized if we assume away the relative consumption comparisons completely such that $\bar{\alpha}=0$, in which case $\beta^{2}>0$ means that the second term on the right-hand side of equation (23) is positive.
} 
the beneficial side effect of relaxing the self-selection constraint through a policy-induced decrease in private consumption, which motivates increased marginal subsidization (or decreased marginal taxation) of charitable giving at the margin.

Finally, note that if $\bar{\alpha}=\alpha^{d}=\beta^{2}=0$, i.e., if neither consumption nor charitable giving were positional goods, then the second term on the right-hand side of equation (23a) would vanish. In this case, there is no longer any discrepancy between the private and social marginal transaction cost of charitable giving, meaning that there is no reason for the government to adjust the marginal subsidy/tax formula in response to the transaction cost. Equation (23a) will then coincide with equation (20a).

\section{Optimal Income Taxation without a Direct Instrument to Control Charitable Giving}

In the previous sections, we examined a case where the government is able to effectively control charitable giving through a direct tax or subsidy. Although this case is interesting and accords well with the idea that high-income consumers may have positional preferences for charitable giving, it is still not necessarily the case that the government is able to target these contributions perfectly through a direct tax instrument. One reason for this is, of course, that charitable contributions are not necessarily fully observable at the individual level. For example, individuals may have an incentive to exaggerate their charitable giving to benefit from the subsidy, or to underreport their contributions to avoid paying the tax. Furthermore, charitable giving is often organized by non-governmental entities with their own interests and incentives. Another reason is that the tax treatment of charitable giving might be politically controversial; in fact, several countries have chosen not to influence the level of charitable giving through direct tax incentives. Therefore, in this section, we analyze a scenario where the government is not able to influence the charitable giving through a direct instrument, i.e., the redistribution and correction policies are solely based on income taxation. ${ }^{23}$ To simplify the analysis, we abstract from the transaction cost of charitable giving addressed in Subsection 3.3, which is not essential for the main insights derived here.

\footnotetext{
${ }^{23}$ An alternative might be to allow for an intermediate case, e.g., a limited form of tax deduction or an arbitrary marginal tax/subsidy. However, as long as the tax treatment of charitable contributions deviates from the flexible policy examined in the previous section, the incentive to affect the charitable contributions through marginal income taxation presented below will prevail. To characterize these tax policy incentives in the simplest possible way, we focus on the extreme case where the government lacks a direct instrument for taxing or subsidizing charitable giving.
} 


\subsection{Individual Behavior}

The tax function will now be written $T^{i}=T\left(w^{i} l^{i}\right)$, as the tax payment (positive or negative) solely depends on the individual's income. The budget constraints facing low-ability and high-ability individuals then become

$$
\begin{aligned}
& w^{1} l^{1}-T\left(w^{1} l^{1}\right)+n^{2} g^{2} / n^{1}-c^{1}=0, \\
& w^{2} l^{2}-T\left(w^{2} l^{2}\right)-g^{2}-c^{2}=0,
\end{aligned}
$$

respectively. The decision problem faced by the low-ability type takes exactly the same form as in the previous section, meaning that equation (5) still represents the first-order condition for work hours. For the high-ability type, the first-order condition for work hours in equation (5) also remains valid, while the first-order condition for charitable giving changes to read

$$
-u_{c}^{2}+u_{g}^{2} \leq 0\left(=0 \text { if } g^{2}>0\right) \text {. }
$$

To be able to influence charitable giving through the income tax, the government may utilize that (25) implicitly defines charitable giving as a function of the private consumption and hours of work of the high-ability type. More specifically, if (25) holds as a strict equality, we can solve for $g^{2}$ as a function of $c^{2}, z^{2}, \bar{c}$, and $\bar{g}^{2}$, i.e., $g^{2}=\breve{g}^{2}\left(c^{2}, z^{2}, \bar{c}, \bar{g}^{2}\right)$. By using $g^{2}=\bar{g}^{2}$, we obtain the reduced form

$$
g^{2}=g^{2}\left(c^{2}, z^{2}, \bar{c}\right) .
$$

Equation (26) is interpretable as the reaction function for $g^{2}$ perceived by the government, since the government recognizes the relationship between $g^{2}$ and $\bar{g}^{2}$. In the general case, the comparative statics of equation (26) are ambiguous. To gain some additional insights and provide intuition, we also consider a simplified version of equation (26) based on a separable utility function for the high-ability type:

$$
U^{2}=v^{2}\left(c^{2}, z^{2}, g^{2}, \Delta c^{2}, \Delta g^{2}\right)=\breve{v}\left(c^{2}, z^{2}\right)+h\left(g^{2}\right)+k\left(\Delta c^{2}\right)+q\left(\Delta g^{2}\right),
$$

where each sub-utility function is increasing in its respective argument and strictly concave, and consumption and leisure are weak (Edgeworth) complements such that $\breve{v}_{c z}^{2} \geq 0$. Then, if $g^{2}>0,(25)$ simplifies to

$$
-\left(\breve{v}_{c}\left(c^{2}, z^{2}\right)+k_{\Delta c}\left(\Delta c^{2}\right)\right)+h_{g}\left(g^{2}\right)+q_{\Delta g}\left(\Delta g^{2}\right)=0 .
$$

Totally differentiating and using $\bar{g}^{2}=g^{2}$ give

$$
\text { (i) } \frac{\partial g^{2}}{\partial c^{2}}>0, \quad \text { (ii) } \frac{\partial g^{2}}{\partial z^{2}} \leq 0, \quad \text { (iii) } \frac{\partial g^{2}}{\partial \bar{c}}<0 \text {. }
$$

The comparative statics in (28b) have straightforward interpretations. An increase in private consumption leads to decreased marginal utility of consumption, which in turn leads the 
individual to redirect spending toward more charitable giving, ceteris paribus. Increased use of leisure instead increases the marginal utility of consumption (by the assumption of complementary) and leads to increased private consumption and less charitable giving, ceteris paribus. Finally, since the individuals are positional in terms of consumption, it follows that an increase in the reference consumption increases the marginal utility of consumption, ceteris paribus, which leads to less charitable giving.

\subsection{The Government}

As in the previous sections, the government attempts to correct for positional externalities, emanating from both consumption and charitable giving, and also to redistribute between the two ability types. In this case, however, it lacks a direct instrument to subsidize or tax charity. By using $g^{1}=-n^{2} g^{2} / n^{1}$ and $\bar{g}^{1}=-n^{2} \bar{g}^{2} / n^{1}$ as before, the public decision problem is to choose $l^{1}, c^{1}, l^{2}$, and $c^{2}$ to maximize utility for the low-ability type while holding utility fixed for the high-ability type subject to the self-selection constraint and the resource constraint, implying that we can write the Lagrangean as

$$
\begin{aligned}
L & =u^{1}\left(c^{1}, z^{1},-n^{2} g^{2} / n^{1}, \bar{c},-n^{2} \bar{g}^{2} / n^{1}\right)+\delta\left[u^{2}\left(c^{2}, z^{2}, g^{2}, \bar{c}, \bar{g}^{2}\right)-\bar{U}^{2}\right] \\
& +\lambda\left[u^{2}\left(c^{2}, z^{2}, g^{2}, \bar{c}, \bar{g}^{2}\right)-\hat{u}^{2}\left(c^{1}, 1-\phi l^{1},-n^{2} g^{2} / n^{1}, \bar{c},-n^{2} \bar{g}^{2} / n^{1}\right)\right] . \\
& +\gamma \sum_{i} n^{i}\left[w^{i} l^{i}-c^{i}\right]
\end{aligned}
$$

However, $g^{2}$ is not a direct choice variable anymore and can therefore only be affected indirectly. It is here instead given by equation (26), i.e., $g^{2}=g^{2}\left(c^{2}, z^{2}, \bar{c}\right)$. We continue to assume that the mimicker does not contribute to charity, which is perhaps somewhat more questionable here, since the model no longer requires that charitable giving is observable to the government. ${ }^{24}$ For purposes of comparison, we would like to keep the model as close as possible to that of the previous section (except that the government can no longer directly control charitable giving), which means that we assume that the mimicker does not contribute to charity.

The social first-order conditions can then be written as

$$
l^{1}:-u_{z}^{1}+\lambda \phi \hat{u}_{z}^{2}+\gamma n^{1} w^{1}=0
$$

\footnotetext{
${ }^{24}$ On the one hand, the mimicker is no longer restricted in his/her contribution behavior and may therefore want to contribute to charitable giving. On the other hand, the mimicker is also a recipient of charity, and it may seem somewhat counterintuitive to contribute to and benefit from charitable giving at the same time. In addition, recall that the mimicker has the same income as the low-ability type.
} 


$$
\begin{array}{ll}
c^{1}: & u_{c}^{1}-\lambda \hat{u}_{c}^{2}-\gamma n^{1}+L_{\bar{c}} \frac{n^{1}}{N}=0, \\
l^{2}: & -(\delta+\lambda) u_{z}^{2}+\gamma n^{2} w^{2}-L_{g^{2}} \frac{\partial g^{2}}{\partial z^{2}}=0, \\
c^{2}: & (\delta+\lambda) u_{c}^{2}-\gamma n^{2}+L_{\bar{c}} \frac{n^{2}}{N}+L_{g^{2}} \frac{\partial g^{2}}{\partial c^{2}}=0 .
\end{array}
$$

The social first-order conditions for $l^{1}$ and $c^{1}$, given by equations (30) and (31), take the same general form as in the previous section. Yet, as we will show below, the marginal income tax rate implemented for the low-ability type will differ from the policy implemented in the previous section due to interaction effects between the positional consumption and gifts externalities. In addition, the social first-order conditions for $l^{2}$ and $c^{2}$ in equations (32) and (33) are directly dependent on the welfare effect of charitable giving (through the partial derivative of the Lagrangean with respect to $g^{2}$ ), since changes in the hours of work and private consumption of the high-ability type affect charitable giving through the reaction function given in equation (26). This will be discussed further below.

To gain further insight into the implications of charitable giving for optimal income taxation, we differentiate the Lagrangean with respect to $\bar{c}$ and $g^{2}$, while using $g^{2}=\bar{g}^{2}$. This gives

$$
\begin{aligned}
& L_{\bar{c}}=u_{\bar{c}}^{1}+(\delta+\lambda) u_{\bar{c}}^{2}-\lambda \hat{u}_{\bar{c}}^{2}+L_{g} \frac{\partial g^{2}}{\partial \bar{c}}, \\
& L_{g^{2}}=(\delta+\lambda) u_{g}^{2}-n^{2}\left(u_{g}^{1}-\lambda \hat{u}_{g}^{2}\right) / n^{1}+L_{\bar{g}^{2}},
\end{aligned}
$$

where

$$
L_{\bar{g}^{2}} \equiv(\delta+\lambda) u_{\bar{g}}^{2}-n^{2}\left(u_{\bar{g}}^{1}-\lambda \hat{u}_{\bar{g}}^{2}\right) / n^{1}
$$

Recall from the previous section that $u_{\bar{c}}^{i}=-\alpha^{i} u_{c}^{i}, \hat{u}_{\bar{c}}^{2}=-\hat{\alpha}^{2} \hat{u}_{c}^{2}$, and $u_{\bar{g}}^{i}=-\beta^{i} u_{g}^{i}$ for $i=1,2$. By using equations (31), (33), (34a), (34b), and (34c), we can then derive

$$
\begin{aligned}
L_{g^{2}} & =(\delta+\lambda) u_{g}^{2}\left(1-\beta^{2}\right)-n^{2}\left(u_{g}^{1}\left(1-\beta^{1}\right)-\lambda \hat{u}_{g}^{2}\left(1-\hat{\beta}^{2}\right)\right) / n^{1} \\
& =(\delta+\lambda) v_{g}^{2}-n^{2}\left(v_{g}^{1}-\lambda \hat{v}_{g}^{2}\right) / n^{1} \\
L_{\bar{c}} & =-\gamma N \frac{\bar{\alpha}-\alpha^{d}}{1-\bar{\alpha}}+\frac{1}{1-\bar{\alpha}}\left((\delta+\lambda) v_{g}^{2}-n^{2}\left(v_{g}^{1}-\lambda \hat{v}_{g}^{2}\right) / n^{1}\right)\left(\frac{\partial g^{2}}{\partial \bar{c}}+\alpha^{2} \frac{\partial g^{2}}{\partial c^{2}}\right) .
\end{aligned}
$$

Note that the right-hand side of equation (35a) can be either positive or negative. It contains the components of the social first-order condition for $g^{2}$ derived in equation (19) in Section 2, although the two terms do not necessarily sum to zero here. The first term on the right-hand 
side of equation (35b) is the direct partial welfare effect of increased reference consumption, which depends on the average degree of consumption positionality, $\bar{\alpha}$, and the difference in the degree of consumption positionality between the mimicker and the low-ability type, $\alpha^{d}$ (as defined in the previous section). We can see that the larger the $\bar{\alpha}$, the greater the welfare cost of increased reference consumption, ceteris paribus. This effect is, in turn, either reinforced $\left(\alpha^{d}<0\right)$ or counteracted $\left(\alpha^{d}>0\right)$ by an incentive to relax the self-selection constraint by exploiting that the mimicker and the low-ability type typically differ in terms of the degree of consumption positionality.

The second term on the right-hand side of equation (35b) is an indirect welfare effect of increased reference consumption and arises because the two externalities interact through the reaction function for $g^{2}$ in equation (26). As such, this component depends on the social cost benefit rule for $g^{2}$ and would, of course, vanish in a setting where the government directly controls charitable giving, in which case the social first-order condition for $g^{2}$ would read $(\delta+\lambda) v_{g}^{2}-n^{2}\left(v_{g}^{1}-\lambda \hat{v}_{g}^{2}\right) / n^{1}=0$, while the right-hand side of equation (35b) would reduce to $L_{\bar{c}}=-\gamma N\left(\bar{\alpha}-\alpha^{d}\right) /(1-\bar{\alpha})$. The multiplier $\partial g^{2} / \partial \bar{c}+\alpha^{2} \partial g^{2} / \partial c^{2}$ reflects two different channels through which the two positional externalities interact. These channels are (i) a direct effect of $\bar{c}$ on $g^{2}$ and, therefore, on $\bar{g}^{2}$, and (ii) a feedback effect because $\bar{c}$ affects $c^{2}$ through equation (33). The latter effect depends on the high-ability type's degree of consumption positionality: the higher this degree, the stronger the feedback effect. According to the comparative statics based on the simplified utility function in equation (27), $\partial g^{2} / \partial \bar{c}<0$ and $\partial g^{2} / \partial c^{2}>0$. Thus, the lower the high-ability type's degree of consumption positionality, the more likely it is that $\partial g^{2} / \partial \bar{c}+\alpha^{2} \partial g^{2} / \partial c^{2}$ is a negative number.

We are now ready to derive the marginal income tax rates, which is accomplished by combining the social first-order conditions in equations (30)-(33) with the private first-order condition for labor supply in equation (5). The marginal income tax policy is summarized in Proposition 3. 
Proposition 3. If the government lacks a direct instrument for controlling charitable giving, the optimal marginal income tax rates can be characterized as

$$
\begin{aligned}
T_{w l}^{1} & =\frac{\lambda^{*}}{n^{1} w^{1}}\left(M R S_{z, c}^{1}-\phi M \hat{R} S_{z, c}^{2}\right)-\frac{L_{\bar{c}}}{w^{1} \gamma N} M R S_{z, c}^{1}, \\
T_{w l}^{2} & =-M R S_{z, c}^{2} \frac{L_{\bar{c}}}{w^{2} \gamma N}+\frac{L_{g^{2}}}{\gamma w^{2} n^{2}}\left(\frac{\partial g^{2}}{\partial z^{2}}-M R S_{z, c}^{i} \frac{\partial g^{2}}{\partial c^{2}}\right),
\end{aligned}
$$

where $\lambda^{*}=\lambda \hat{u}_{c}^{2} / \gamma, M R S_{z, c}^{i}=\frac{u_{z}^{i}}{u_{c}^{i}}$ for $i=1,2$, and $M \hat{R} S_{z, c}^{2}=\frac{\hat{u}_{z}^{2}}{\hat{u}_{c}^{2}}$.

Proof: See the Appendix.

The low-ability type's marginal income tax rate given in equation (36a) takes the same general form as in Aronsson and Johansson-Stenman (2008), with the modification that the welfare effect of increased reference consumption is now given by equation (35b). As a consequence, the sign of the second term on the right-hand side no longer depends only on the difference $\alpha^{d}-\bar{\alpha}$ (as it did in Section 3), but also on whether an increase in $g^{2}$ leads to higher or lower social welfare. An analogous effect appears as the first term on the right-hand side in the marginal income tax formula for the high-ability type given in equation (36b).

To provide intuition behind the tax policy implications of consumption positionality, and in particular the implications of the second term on the right-hand side of equation (35b), we add the (reasonable) assumption that $\bar{\alpha}>\alpha^{d}$, in which case the first term on the right-hand side of equation (35b) is negative, and then use the simplified utility function given in equation (27) and associated comparative statics in (28b). It follows that the partial welfare effect of increased reference consumption, as specified in equation (35b), is negative if

$$
\left((\delta+\lambda) v_{g}^{2}-n^{2}\left(v_{g}^{1}-\lambda \hat{v}_{g}^{2}\right) / n^{1}\right)\left[\frac{\partial g^{2}}{\partial \bar{c}}+\alpha^{2} \frac{\partial g^{2}}{\partial c^{2}}\right]<0,
$$

where $\partial g^{2} / \partial \bar{c}<0$ and $\partial g^{2} / \partial c^{2}>0$ from (28b). Since the functional form assumption for the utility function implies $\left|\partial g^{2} / \partial c^{2}\right|>\left|\partial g^{2} / \partial \bar{c}\right|$, the sign of the term in square bracket depends on the high-ability type's degree of consumption positionality. If this degree is sufficiently high, such that $\partial g^{2} / \partial \bar{c}+\alpha^{2} \partial g^{2} / \partial c^{2}>0$, the negative sign of (37) requires that charity is over-provided relative to the second-best optimal provision rule in Section 2, i.e., 
$(\delta+\lambda) v_{g}^{2}<n^{2}\left(v_{g}^{1}-\lambda \hat{v}_{g}^{2}\right) / n^{1}$. This exemplifies an incentive to increase the marginal income tax rates for both ability types that in turn leads to a smaller positional consumption externality as well as a simultaneous decrease in the level of charitable giving (both of which are desirable).

Instead, if the high-ability type's degree of consumption positionality is low enough such that $\partial g^{2} / \partial \bar{c}+\alpha^{2} \partial g^{2} / \partial c^{2}<0$, and if we continue to assume that charitable giving is overprovided in equilibrium relative to the second-best optimal policy rule, (37) will be replaced with

$$
\left((\delta+\lambda) v_{g}^{2}-n^{2}\left(v_{g}^{1}-\lambda \hat{v}_{g}^{2}\right) / n^{1}\right)\left(\frac{\partial g^{2}}{\partial \bar{c}}+\alpha^{2} \frac{\partial g^{2}}{\partial c^{2}}\right)>0 .
$$

In this case, the two terms on the right-hand side of equation (35b) differ in sign (under the assumption that $\bar{\alpha}>\alpha^{d}$ ), meaning that the marginal tax policy implication of the positional consumption externality is ambiguous (since a decrease in this externality would lead to an increase in the already over-provided charitable giving).

Policy implications opposite to those just discussed would follow if charitable giving were under-provided in equilibrium relative to the second-best optimal policy rule, i.e., if $(\delta+\lambda) v_{g}^{2}>n^{2}\left(v_{g}^{1}-\lambda \hat{v}_{g}^{2}\right) / n^{1}$.

The second term on the right-hand side of equation (36b) is also novel and arises because the high-ability type's labor supply and consumption choices directly affect the charitable giving and, therefore, the tax policy incentives. Note first that this effect has nothing to do with consumption positionality (i.e., it would be present also in a model without consumption positionality where $L_{\bar{c}}=0$ ). To provide intuition, consider once again the simplified utility function with comparative statics in $(28 \mathrm{~b})$, in which case

$$
\frac{\partial g^{2}}{\partial z^{2}}-M R S_{z, c}^{2} \frac{\partial g^{2}}{\partial c^{2}}<0
$$

With (39) at our disposal, it follows that the second term on the right-hand side of equation (36b) constitutes an incentive to tax high-ability labor at the margin if $(\delta+\lambda) v_{g}^{2}<n^{2}\left(v_{g}^{1}-\lambda \hat{v}_{g}^{2}\right) / n^{1}$. In this scenario, the high-ability type over-provides charitable donations relative to the policy rule ideally preferred by the government in equation (19). Therefore, by reducing the high-ability type's labor supply and disposable income, less will 
be spent on charitable giving. If instead $(\delta+\lambda) v_{g}^{2}>n^{2}\left(v_{g}^{1}-\lambda \hat{v}_{g}^{2}\right) / n^{1}$, meaning that the highability type under-provides charitable donations in equilibrium, there is an analogous incentive to reduce the marginal income tax rate facing the high-ability type. The intuition is that lower marginal income taxation leads to increased charitable giving, which is desirable as long as giving falls below the level implied by equation (19).

Finally, note that equation (36a) and (36b) would coincide with equation (18a) and (18b) if

$$
L_{g^{2}}=(\delta+\lambda) v_{g}^{2}-n^{2}\left(v_{g}^{1}-\lambda \hat{v}_{g}^{2}\right) / n^{1}=0
$$

i.e., if the marginal welfare contribution of charitable giving is zero at the optimum. This would be the case if the government were able to control the charitable donations through a direct instrument, as in Sections 2 and 3. Therefore, the fact that charitable giving is no longer necessarily at the socially optimal level (due to the lack of such an instrument) is the source of discrepancy between the policy rules for marginal income taxation given in equations (36) and those presented in Section 3.

\section{Numerical Simulations}

In this section, we simulate numerical versions of the models set out and examined in Sections 3 and 4. This makes it possible to quantify the importance of various mechanisms characterizing the policy rules for marginal taxation presented above. It also enables us to go beyond the policy rules by analyzing the levels of marginal taxation, and the overall redistribution policy. The main aim is to examine (i) how the two versions of the model (i.e., with and without a direct tax instrument for controlling charitable giving) differ in terms of marginal tax and redistribution policy and (ii) how the optimal tax and redistribution policies vary with key parameters of the model.

\subsection{Numerical Model}

Note that the policy rules for marginal taxation presented in Sections 3 and 4 are necessary conditions for maximizing any social welfare function that fulfills the Pareto criterion, as long as it is consistent with the assumption that the policy maker redistributes from the high-ability to the low-ability type. Furthermore, we did not make any specific assumption about the functional form of the individual utility functions. However, when examining the levels of marginal and average taxation, and to be able to quantify the overall redistribution policy, we must specify both the individual utility functions and the social welfare function. 
We assume that all individuals share a common utility function, characterized by the same degree of consumption positionality for all equal to $\alpha$, as well as a common degree of gift positionality equal to $\beta$. We also assume that individuals derive additional utility from giving if, and only if, their own consumption level (or net income) is larger than the consumption level of the recipients. Therefore, only high-ability individuals may donate, and only lowability individuals will potentially receive charitable donations.

The utility related to the warm glow of donating for individual $i$ is given by $v \ln \left(M+D\left(\right.\right.$ give $\left.\left.e^{i}-\beta \overline{\text { give }}^{i}\right)\right)$, where $D$ is a dummy variable taking the value 1 when the receiver has a lower consumption level than oneself and zero otherwise. The corresponding disutility of receiving donations for individual $i$ then becomes $\sigma \ln \left(M+\right.$ receive $\left.e^{i}-\beta \overline{\text { receive }}^{i}\right)$. In equilibrium, only the high-ability individuals will potentially give donations and the lowability individuals potentially receive such donations, meaning that the utility functions facing the two types can be written as follows: ${ }^{25}$

$$
\begin{gathered}
U^{1}=\ln \left(c^{1}-\alpha \bar{c}\right)+\eta \ln \left(z^{1}\right)+v \ln (M)-\sigma \ln \left(M-g^{1}+\beta \bar{g}^{1}\right), \\
U^{2}=\ln \left(c^{2}-\alpha \bar{c}\right)+\eta \ln \left(z^{2}\right)+v \ln \left(M+g^{2}-\beta \bar{g}^{2}\right)-\sigma \ln (M) .
\end{gathered}
$$

Note that these utility functions are leisure separable according to equation (3). Consider first the case where the government can control the charitable giving through a direct instrument. Based on equations (40), and by assuming that the resource cost of charitable giving takes the form $\mu\left(g^{2}\right)=\varepsilon \sqrt{g^{2}}$ for $\varepsilon>0$, the private first-order conditions become ${ }^{26}$

$$
\begin{aligned}
& \operatorname{MRS}_{z c}^{1}=\eta \frac{c^{1}-\alpha \bar{c}}{z^{1}}=w^{1}\left(1-T_{w l}^{1}\right), \\
& \operatorname{MRS}_{z c}^{2}=\eta \frac{c^{2}-\alpha \bar{c}}{z^{2}}=w^{2}\left(1-T_{w l}^{2}\right), \\
& \operatorname{MRS}_{g c}^{2}=v \frac{c^{2}-\alpha \bar{c}}{M+g^{2}-\beta \bar{g}^{2}}=1+T_{g}^{2}+0.5 \varepsilon\left(g^{2}\right)^{-0.5}
\end{aligned}
$$

By analogy to equation (41c), we can derive the marginal rate of substitution between gifts and private consumption for the low-ability type:

\footnotetext{
${ }^{25}$ Similar functional form assumptions are used in other literature on optimal taxation under social comparisons; see Kanbur and Tuomala (2013) and Aronsson and Johansson-Stenman (2018). The latter study assumes a difference comparison, as we have done, whereas the former instead assumes a ratio comparison form.

${ }^{26}$ It is not entirely clear to us whether the cost of charitable giving should be concave (as we assume) or convex (which is the conventional assumption for cost functions). We base our formulation on the assumption that the initial cost of searching among presumptive charities is the main mechanism behind this cost.
} 


$$
M R S_{g c}^{1}=\sigma \frac{c^{1}-\alpha \bar{c}}{M-g^{1}+\beta \bar{g}^{1}} .
$$

Note that $M$ must be large enough such that low-ability individuals accept donations at a zero donation level, i.e., such that $M R S_{g x}^{1}<1$ when $g^{2}=0$, in turn implying $M>\sigma\left(c^{1}-\alpha \bar{c}\right)$ in equilibrium. It must also be small enough to ensure that high-ability individuals are willing to donate at a zero donation level, i.e., $M R S_{g x}^{2}>1$ for $g^{2}=0$, in turn implying that $M<v\left(c^{2}-\alpha \bar{c}\right)$ in equilibrium.

If the government cannot control charitable giving through a direct instrument, the private first-order conditions for work hours remain as above, while equation (41c) is replaced with

$$
M R S_{g c}^{2}=v \frac{c^{2}-\alpha \bar{c}}{M+g^{2}-\beta \bar{g}^{2}}=1+0.5 \varepsilon\left(g^{2}\right)^{-0.5} .
$$

Therefore, by using $g^{2}=\bar{g}^{2}$, equation (43) implicitly defines $g^{2}$ as a function of $c^{2}$ and $\bar{c}$, which constitutes the reaction function through which the government may influence the charitable giving via the income tax.

Turning to the optimal tax problem, we follow much earlier literature in assuming a utilitarian social welfare function:

$$
W=n^{1} U^{1}+n^{2} U^{2}
$$

The self-selection and resource constraints can be written as:

$$
\begin{aligned}
& \ln \left(c^{2}-\alpha \bar{c}\right)+\eta \ln \left(z^{2}\right)+v \ln \left(M+g^{2}-\beta \bar{g}^{2}\right)-\sigma \ln (M) \\
& \geq \ln \left(c^{1}-\alpha \bar{c}\right)+\eta \ln \left(1-\phi l^{1}\right)+v \ln (M)-\sigma \ln \left(M+\left(g^{2}-\beta \bar{g}^{2}\right) n^{2} / n^{1}\right), \\
& \sum_{i=1}^{2} n^{i} w^{i} l^{i}=\sum_{i=1}^{2} n^{i} c^{i}+n^{2} \varepsilon \sqrt{g^{2}},
\end{aligned}
$$

where we have used $g^{1}=-n^{2} g^{2} / n^{1}$. In the version of the model where the government can control the charitable giving through a direct tax instrument, the social decision-problem is to choose $l^{1}, c^{1}, l^{2}, c^{2}$, and $g^{2}$ to maximize the social welfare function given in equation (44) subject to the self-selection and resource constraints in equations (45) and (46). In doing so, the government (or social planner) also recognizes that the two reference measures are endogenous and given by $\bar{c}=(1 / N) \sum_{i} n^{i} c^{i}$ and $\bar{g}^{2}=g^{2}$, respectively. By analogy, if the government lacks a direct tax instrument for controlling charitable giving, the social decisionproblem is to choose $l^{1}, c^{1}, l^{2}$, and $c^{2}$ to maximize the social welfare function subject to the 
same self-selection and resource constraints, and subject to the reaction function for $g^{2}$ implicitly defined by equation (43).

\subsection{Baseline Simulation Results}

In the baseline setting, we assume a substantial productivity differential between the types and that the degrees of positionality are relatively modest (equal to 0.2 for both consumption and charitable giving). The baseline parameters are the following: $=0.2,=0.2,=0.5$, $=0.4, \quad=0.4, v=0.4, M=5, n^{1}=0.8, n^{2}=0.2, w^{1}=15$, and $w^{2}=60$. Average income tax rates will be denoted $\bar{T}^{1}$ (for low-ability individuals) and $\bar{T}^{2}$ (for high-ability individuals); all other notations are the same as above.

Table 1 Baseline Results

1a) Direct instrument for controlling charitable giving

\begin{tabular}{cccccccccc}
\hline$c^{1}$ & $c^{2}$ & $g^{2}$ & $l^{1}$ & $l^{2}$ & $T_{w l}^{1}$ & $T_{w l}^{2}$ & $\bar{T}^{1}$ & $\bar{T}^{2}$ & $T_{g}^{2}$ \\
\hline 15.29 & 22.19 & 3.39 & 0.56 & 0.84 & 0.27 & 0.20 & -0.71 & 0.48 & -0.16 \\
\hline
\end{tabular}

1b) No direct instrument for controlling charitable giving

\begin{tabular}{cccccccccc}
\hline$c^{1}$ & $c^{2}$ & $g^{2}$ & $l^{1}$ & $l^{2}$ & $T_{w l}^{1}$ & $T_{w l}^{2}$ & $\bar{T}^{1}$ & $\bar{T}^{2}$ & Shadow value of $g^{2}: L_{g^{2}}$ \\
\hline 15.13 & 23.16 & 2.24 & 0.57 & 0.84 & 0.28 & 0.17 & -0.72 & 0.48 & 0.11 \\
\hline
\end{tabular}

In both parts of Table 1, we can observe a sizable redistribution through income taxes. Indeed, the average tax is around -70 percent for low-ability individuals (and about 50 percent for high-ability individuals), meaning that they will receive about 0.7 USD as a tax transfer per dollar earned; yet, their marginal tax rate is positive and equal to $27-28$ per cent. Furthermore, despite that a first-best tax policy would equalize the consumption across individuals - due to the functional form assumptions for the individual utility functions and the social welfare function - the second-best allocation portrayed here implies a substantial inequality measured in terms of consumption, although it is substantially smaller than in terms of the before-tax wage rates. Thus, the self-selection constraint effectively reduces the scope for redistribution. Nevertheless, given this level of governmental redistribution through taxes, Table 1a shows that it is still optimal to subsidize charitable giving, with a subsidy rate of 16 percent. The resulting redistribution through charity is also far from negligible. 
Table 1b illustrates the case where the government lacks a direct instrument for influencing charitable donations (implying of course that $T_{g}^{2}=0$ ) and presents results reminiscent of those in Table 1a, but with two important exceptions. First, without a direct instrument for influencing charitable giving, these donations are smaller at the optimum. In turn, this means that the high-ability individuals consume more and the low-ability individuals consume less in Table $1 \mathrm{~b}$ than in Table 1a. Therefore, a full set of instruments allows for more redistribution without violating the self-selection constraint.

Second, and more interestingly, the marginal income tax rate implemented for the high-ability type is lower here than in Table 1a. The intuition is that the charitable giving is underprovided relative to the policy rule ideally preferred by the government, implying that the government now uses the marginal income tax faced by the high-ability type as an indirect instrument for increasing the level of charitable giving. This mechanism is illustrated in equation (36b): since the shadow value of charitable giving $L_{g^{2}}>0$ in Table $1 \mathrm{~b}$ (meaning that increased charitable giving leads to higher social welfare, ceteris paribus), the second term on the right-hand side of equation (36) is negative and thus contributes to a lower marginal income tax rate. Note that this mechanism is absent in the simulation results presented in Table 1a, where the government has a direct instrument for influencing the charitable giving and uses this instrument such that $L_{g^{2}}=0$.

We would, nevertheless, like to point out that the marginal and average income tax policies are quite similar in Tables $1 \mathrm{a}$ and $1 \mathrm{~b}$, despite that the direct tax/subsidy instrument for charitable giving is absent in the simulations underlying Table 1b. In other words, the benchmark simulations imply that the marginal income tax policies and overall redistribution are not very sensitive to whether the government can control the charitable giving through a direct instrument. This suggests that the marginal income tax is a somewhat weak instrument from the perspective of targeting charitable contributions, which is further emphasized by the discrepancy between Tables $1 \mathrm{a}$ and $1 \mathrm{~b}$ regarding the level of these donations.

\subsection{Sensitivity Analyses}

In this subsection, we present a number of sensitivity analyses to examine how the results of the benchmark simulations will change in response to variations in the degree of consumption positionality, $\alpha$, the degree of gifts positionality, $\beta$, the measure of stigma attached to 
charitable donations, $\sigma$, and the relative wage rate, $w^{2} / w^{1}$, respectively. Variations in each such parameter will be addressed in turn, where the other parameters take the same values as in the benchmark model.

Table 2. Varying the degree of consumption positionality, $\alpha$

2a) Direct instrument for controlling charitable giving

\begin{tabular}{ccccccccccc}
\hline$\alpha$ & $c^{1}$ & $c^{2}$ & $g^{2}$ & $l^{1}$ & $l^{2}$ & $T_{w l}^{1}$ & $T_{w l}^{2}$ & $\bar{T}^{1}$ & $\bar{T}^{2}$ & $T_{g}^{2}$ \\
\hline 0 & 14.94 & 23.57 & 3.39 & 0.56 & 0.84 & 0.09 & 0 & -0.67 & 0.45 & 0.09 \\
0.05 & 15.03 & 23.22 & 3.39 & 0.56 & 0.84 & 0.14 & 0.05 & -0.68 & 0.46 & 0.03 \\
0.25 & 15.37 & 21.84 & 3.39 & 0.56 & 0.84 & 0.28 & 0.25 & -0.72 & 0.48 & -0.22 \\
0.45 & 15.72 & 20.46 & 3.39 & 0.56 & 0.84 & 0.50 & 0.45 & -0.77 & 0.51 & -0.46 \\
0.65 & 16.06 & 19.08 & 3.39 & 0.56 & 0.84 & 0.68 & 0.65 & -0.81 & 0.54 & -0.71 \\
0.85 & 16.41 & 17.70 & 3.39 & 0.56 & 0.84 & 0.86 & 0.85 & -0.85 & 0.56 & -0.95 \\
\hline
\end{tabular}

2b) No direct instrument for controlling charitable giving

\begin{tabular}{ccccccccccc}
\hline$\alpha$ & $c^{1}$ & $c^{2}$ & $g^{2}$ & $l^{1}$ & $l^{2}$ & $T_{w l}^{1}$ & $T_{w l}^{2}$ & $\bar{T}^{1}$ & $\bar{T}^{2}$ & Shadow value of $g^{2}: L_{g^{2}}$ \\
\hline 0 & 15.04 & 23.02 & 3.98 & 0.56 & 0.84 & 0.09 & 0.02 & -0.67 & 0.45 & -0.05 \\
0.05 & 15.06 & 23.06 & 3.57 & 0.56 & 0.84 & 0.14 & 0.06 & -0.68 & 0.45 & -0.01 \\
0.25 & 15.16 & 23.21 & 1.75 & 0.57 & 0.84 & 0.32 & 0.20 & -0.73 & 0.49 & 0.15 \\
0.45 & 15.51 & 23.13 & 0 & 0.58 & 0.84 & 0.51 & 0.34 & -0.79 & 0.54 & 0 \\
0.65 & 15.98 & 20.67 & 0 & 0.57 & 0.84 & 0.69 & 0.60 & -0.86 & 0.59 & 0 \\
0.85 & 16.39 & 18.32 & 0 & 0.57 & 0.83 & 0.87 & 0.84 & -0.92 & 0.63 & 0 \\
\hline
\end{tabular}

Tables $2 \mathrm{a}$ and $2 \mathrm{~b}$ show that the marginal income tax rates increase with the degree of consumption positionality, which is in line with earlier studies on optimal nonlinear income taxation under relative consumption concerns based on numerical models (e.g., Kanbur and Tuomala, 2013; Aronsson and Johansson-Stenman, 2018). As implied by equation (18), the marginal income tax rate implemented for the high-ability type always equals the common degree of consumption positionality in Table $2 \mathrm{a}$, since there is no discrepancy in the degree of positionality between the mimicker and the low-ability type when the utility function takes the form of equation (40). The marginal income tax rate facing the low-ability type analogously exceeds the common degree of consumption positionality due to that marginal taxation of low-ability individuals also constitutes a means of relaxing the self-selection constraint (by exploiting that a potential mimicker and mimicked agent differ in terms of the 
marginal valuation of leisure). Another distinguishing feature is that the redistribution among consumer types increases substantially with the degree of consumption positionality.

We can also note from Table 2a that the optimal marginal subsidy for charitable giving increases with the degree of consumption positionality. In fact, when $\alpha$ increases from zero, $T_{g}^{2}$ goes from a positive number (a marginal tax) to a negative number (marginal subsidy). As shown in the theoretical section, there are two simultaneous forces at work here. First, the higher the $\alpha$, the lower the marginal willingness to pay among low-ability individuals to avoid stigma. Second, positionality in private consumption induces the high-ability type to overestimate the social marginal cost of charitable giving (and for this reason to spend less resources on charity), which also contributes to increase the marginal subsidy.

Finally, the marginal and average tax rates, as well as the distribution of consumption, are qualitatively similar regardless of whether the government can control the charitable giving through a direct instrument.

Table 3 Varying the degree of gifts positionality, $\beta$

3a) Direct instrument for controlling charitable giving

\begin{tabular}{ccccccccccc}
\hline$\beta$ & $c^{1}$ & $c^{2}$ & $g^{2}$ & $l^{1}$ & $l^{2}$ & $T_{w l}^{1}$ & $T_{w l}^{2}$ & $\bar{T}^{1}$ & $\bar{T}^{2}$ & $T_{g}^{2}$ \\
\hline 0 & 15.33 & 22.12 & 2.83 & 0.56 & 0.84 & 0.27 & 0.20 & -0.74 & 0.49 & -0.19 \\
0.20 & 15.29 & 22.19 & 3.39 & 0.56 & 0.84 & 0.29 & 0.20 & -0.71 & 0.48 & -0.16 \\
0.40 & 15.23 & 22.30 & 4.22 & 0.56 & 0.84 & 0.28 & 0.20 & -0.68 & 0.45 & -0.11 \\
0.60 & 15.14 & 20.50 & 5.53 & 0.56 & 0.84 & 0.28 & 0.20 & -0.63 & 0.42 & -0.04 \\
0.80 & 14.89 & 23.18 & 6.51 & 0.57 & 0.83 & 0.29 & 0.20 & -0.56 & 0.38 & 0.16 \\
\hline
\end{tabular}

3b) No direct instrument for controlling charitable giving

\begin{tabular}{ccccccccccc}
\hline$\beta$ & $c^{1}$ & $c^{2}$ & $g^{2}$ & $l^{1}$ & $l^{2}$ & $T_{w l}^{1}$ & $T_{w l}^{2}$ & $\bar{T}^{1}$ & $\bar{T}^{2}$ & Shadow value of $g^{2}: L_{g^{2}}$ \\
\hline 0 & 15.13 & 23.32 & 1.70 & 0.57 & 0.84 & 0.28 & 0.16 & -0.73 & 0.49 & 0.16 \\
0.20 & 15.06 & 23.16 & 2.24 & 0.57 & 0.84 & 0.28 & 0.17 & -0.72 & 0.48 & 0.11 \\
0.40 & 15.12 & 22.97 & 3.14 & 0.56 & 0.84 & 0.28 & 0.18 & -0.69 & 0.47 & 0.05 \\
0.60 & 15.10 & 22.74 & 4.95 & 0.56 & 0.84 & 0.28 & 0.19 & -0.64 & 0.43 & 0.01 \\
0.80 & 15.02 & 22.37 & 10.40 & 0.56 & 0.84 & 0.29 & 0.22 & -0.47 & 0.32 & -0.02 \\
\hline
\end{tabular}


We can see from Table 3a that none of the marginal income tax rates are very sensitive to changes in the degree of gifts positionality. The reason is that the government has a perfect instrument for influencing charitable giving (by construction of the model), meaning that the positionality in donations does not directly affect the policy rules for marginal income taxation. Therefore, the marginal income tax rate facing the high-ability type remains constant and equal to the degree of consumption positionality, while the marginal income tax rate implemented for the low-ability type varies slightly due to that a change in $\beta$ may either tighten or relax the self-selection constraint.

In Table 3a, the optimal marginal subsidy for charitable donations decreases in response to an increase in $\beta$ and eventually turns into a marginal tax. An increase in $\beta$ means that a larger fraction of the high-ability type's marginal utility of charitable giving is social waste and that there is a greater tendency for the high-ability type to underestimate the social marginal cost of charitable giving. Both of these effects work to decrease the marginal subsidy for such donations. In Table $3 b$, where the simulations are based on the assumption that the government cannot directly tax or subsidize charitable contributions, the analogous (albeit indirect) policy response is to increase the marginal income tax rate facing the high-ability type to weaken the incentive for charitable contributions as $\beta$ increases. The pattern of the average tax rates and distribution of consumption is similar across the two parts of the table: the government redistributes less via the tax system when the charitable donations increase.

Table 4 Variation in the marginal disutility of receiving charitable donations, $\sigma$ 4a) Direct instrument for controlling charitable giving

\begin{tabular}{ccccccccccc}
\hline$\sigma$ & $c^{1}$ & $c^{2}$ & $g^{2}$ & $l^{1}$ & $l^{2}$ & $T_{w l}^{1}$ & $T_{w l}^{2}$ & $\bar{T}^{1}$ & $\bar{T}^{2}$ & $T_{g}^{2}$ \\
\hline 0.1 & 16.83 & 16.33 & 37.26 & 0.55 & 0.89 & 0.19 & 0.20 & 0.09 & -0.06 & -0.89 \\
0.3 & 15.66 & 20.86 & 6.58 & 0.56 & 0.85 & 0.25 & 0.20 & -0.67 & 0.44 & -0.41 \\
0.5 & 14.95 & 23.40 & 1.40 & 0.56 & 0.83 & 0.29 & 0.20 & -0.73 & 0.49 & 0.10 \\
\hline
\end{tabular}

4b) No direct instrument to controlling charitable giving

\begin{tabular}{ccccccccccc}
\hline$\sigma$ & $c^{1}$ & $c^{2}$ & $g^{2}$ & $l^{1}$ & $l^{2}$ & $T_{w l}^{1}$ & $T_{w l}^{2}$ & $\bar{T}^{1}$ & $\bar{T}^{2}$ & Shadow value of $g^{2}: L_{g^{2}}$ \\
\hline 0.1 & 15.31 & 24.49 & 2.94 & 0.58 & 0.86 & 0.25 & -0.04 & -0.68 & 0.45 & 0.66 \\
0.3 & 15.20 & 23.57 & 2.46 & 0.57 & 0.85 & 0.27 & 0.11 & -0.71 & 0.46 & 0.28 \\
0.5 & 15.05 & 22.77 & 2.02 & 0.56 & 0.83 & 0.29 & 0.22 & -0.73 & 0.49 & -0.06 \\
\hline
\end{tabular}


Table $4 \mathrm{a}$ shows that the size of the donation per high-ability individual and the marginal subsidy for donations fall substantially when the stigma attached to receiving charitable donations increases. If the stigma is sufficiently high (represented by $\sigma=0.5$ in the table), charitable giving should be taxed at the margin. In Table $4 \mathrm{~b}$, the analogous policy response is to increase the marginal income tax rate implemented for the high-ability type when the stigma attached to charitable contributions increases. Here, the co-variation between the charitable contributions and $\sigma$ is much smaller than in Table $4 \mathrm{a}$, indicating once again that marginal income taxation is not an effective means of influencing charitable giving.

Table 5. Variation in the relative wage rate, $w^{2} / w^{1}$, where $w^{1}=15$

5a) Direct instrument for controlling charitable giving

\begin{tabular}{ccccccccccc}
\hline$w^{2} / w^{1}$ & $c^{1}$ & $c^{2}$ & $g^{2}$ & $l^{1}$ & $l^{2}$ & $T_{w l}^{1}$ & $T_{w l}^{2}$ & $\bar{T}^{1}$ & $\bar{T}^{2}$ & $T_{g}^{2}$ \\
\hline 3 & 13.50 & 19.10 & 2.44 & 0.62 & 0.82 & 0.27 & 0.20 & -0.39 & 0.40 & -0.23 \\
4 & 15.29 & 22.19 & 3.39 & 0.56 & 0.84 & 0.27 & 0.20 & -0.71 & 0.48 & -0.16 \\
6 & 18.93 & 28.25 & 4.52 & 0.45 & 0.87 & 0.28 & 0.20 & -1.63 & 0.57 & 0 \\
8 & 22.62 & 34.24 & 5.20 & 0.34 & 0.88 & 0.29 & 0.20 & -3.16 & 0.61 & 0.17 \\
10 & 26.32 & 40.20 & 5.61 & 0.23 & 0.89 & 0.29 & 0.20 & -6.18 & 0.65 & 0.34 \\
\hline
\end{tabular}

5b) No direct instrument for controlling charitable giving

\begin{tabular}{ccccccccccc}
\hline$w^{2} / w^{1}$ & $c^{1}$ & $c^{2}$ & $g^{2}$ & $l^{1}$ & $l^{2}$ & $T_{w l}^{1}$ & $T_{w l}^{2}$ & $\bar{T}^{1}$ & $\bar{T}^{2}$ & $\begin{array}{c}\text { Shadow value of } g^{2}: \\
L_{g^{2}}\end{array}$ \\
\hline 3 & 13.35 & 21.02 & 0.79 & 0.63 & 0.83 & 0.26 & 0.06 & -0.40 & 0.40 & 0.01 \\
4 & 15.13 & 23.16 & 2.24 & 0.57 & 0.84 & 0.28 & 0.17 & -0.72 & 0.48 & 0.11 \\
6 & 18.93 & 28.24 & 4.53 & 0.45 & 0.87 & 0.28 & 0.20 & -1.63 & 0.57 & 0 \\
8 & 22.85 & 32.99 & 6.51 & 0.34 & 0.88 & 0.28 & 0.23 & -3.21 & 0.61 & -0.07 \\
10 & 26.82 & 37.45 & 8.32 & 0.22 & 0.89 & 0.28 & 0.25 & -6.51 & 0.65 & -0.12 \\
\hline
\end{tabular}

According to Tables 5a and 5b, an increased wage differential reduces the hours of work for the low-ability type and increases the hours of work for the high-ability type. At the same time, the tax system becomes more redistributive (as seen by the average tax rates). The charitable donation per high-ability individual increases with the relative wage, i.e., the more productive the high-ability type relative to the low-ability type, the larger the donation will be in absolute value. Note also from Table 5a that the donations increase when the relative wage rate increases, while the marginal subsidy for these donations decreases and eventually turns 
into a marginal tax. In the absence of a direct instrument for influencing charitable giving, we can see from the final column of Table $5 \mathrm{~b}$ that the charitable giving is under-provided (relative to the policy rule ideally preferred by the government) for moderate wage differentials and over-provided for high wage differentials. The latter explains why the charitable giving is more sensitive to variation in the relative wage rate in Table $5 \mathrm{~b}$ than in Table 5a (where the charitable giving satisfies the social first-order condition given in equation [22]).

\section{Conclusions}

Taking the rapidly increased inequality in many countries as the point of departure, this paper analyzes the optimal tax policy implications of private redistribution through charitable giving from richer to poorer individuals based on a two-type model of optimal nonlinear income taxation. We consider a rich behavioral model where receiving charity is associated with a stigma effect, while potential givers are motivated not only by warm glow but also by status concerns. The latter means that donors derive utility from giving more than referent others. Furthermore, since charitable giving reflects a tradeoff between donations and private consumption, status concerns with respect to consumption are not only relevant from the perspective of income taxation; they are also directly relevant for tax policies aimed at influencing charitable donations. Consequently, in our study, both the consumption and charitable giving choices (partly) reflect social comparisons, which also accords well with empirical evidence.

An important take-home message of the paper is that the warm glow of giving and stigma of receiving charity play crucial roles for whether charitable giving should be subsidized or taxed at the margin. In a first-best resource allocation, where the self-selection constraint does not bind, and in the absence of any transaction cost of charitable contributions, a necessary condition for subsidizing charity at the margin is that givers experience a warm glow. Yet, in a second-best resource allocation with a binding self-selection constraint, it may be optimal to subsidize charitable giving at the margin also in the absence of any warm glow, since the stigma effect of receiving charity contributes to relax the self-selection constraint. When introducing transaction costs of charitable giving in the model, we find that the marginal transaction cost contributes to marginal subsidization (taxation) of charitable giving if the positional consumption externality exceeds (falls short of) the positional gift externality. The 
intuition is that these externalities lead to a discrepancy between the public and private marginal cost of charitable giving. Overall, and based on our analysis, there are cases both for taxing and for subsidizing charitable giving.

We also characterize the optimal marginal income tax policy in a more restrictive - albeit empirically relevant - case where the government lacks a direct instrument for taxing or subsidizing charitable giving, and derived conditions under which this results in higher or lower marginal income taxes implemented for both ability types. Whether this additional restriction motivates higher or lower marginal income tax rates (compared with the more general model with a full set of tax instruments) largely depends on whether it leads to overor under-provision of charitable giving relative to the policy rule ideally preferred by the government.

The numerical analysis supports the theoretical results derived in Sections 3 and 4 as well as quantifies the mechanisms driving the optimal tax structure in general and the optimal tax treatment of charitable giving in particular. While the baseline simulation suggests that charitable giving should be subsidized at the margin, variation in key parameters confirms that there are cases where charitable giving ought to be subsidized at the margin and cases where it ought to be taxed. For instance, by increasing the parameter reflecting the social stigma of receiving charity, while holding the other parameters constant, the marginal subsidy rapidly declines and turns, eventually, into a marginal tax. A similar result follows through (ceteris paribus) increases in the degree of gifts positionality, where charitable giving becomes more and more wasteful from society's point of view. The opposite effects emerge from variation in the degree of consumption positionality, where very low levels of this degree may motivate taxation of charitable giving, while higher levels (some of which are in accordance with empirical evidence) motivate subsidization. Another important insight from our analysis is that both versions of the numerical model, i.e., the one with a full set of tax instruments and the one where the government lacks a direct instrument for influencing the level of charitable giving, result in very similar allocations in terms of consumption and work hours. In fact, the results from these two models primarily differ in the level of charitable giving with a corresponding adjustment in terms of the average income tax rates. This suggests that (i) the income tax alone can accomplish roughly the same redistribution as can be accomplished under a mix of taxes on income and charitable giving, although at a higher social cost, and that (ii) the income tax alone constitutes a very weak instrument for 
influencing the level of charitable giving.

Although the present paper has generalized previous research in many ways, the results of course still depend on the strong assumptions made in order to be able to understand the key mechanisms involved. For example, whereas we have relied on a two-type model, a generalization to a model with many ability-types (or a model with a continuous ability distribution) would be more complex and require additional assumptions, in particular with respect to both tails of the ability distribution. By way of illustration, assuming that people would prefer to give to those with the lowest-income level, this would induce individuals of the second-lowest income level to mimic the lowest one, in turn implying potential optimal bunching at the lowest income level (i.e., also for the case where the lowest ability-type chooses to work at the optimum). Such mechanisms are important, both theoretically and of course even more so when modifying actual tax systems in practice, and deserve further attention in future research. Still, the key insights from the mechanisms analyzed here would still prevail.

Similarly, in our model there is only one type of voluntary contribution, whereas in reality there are many different types of charitable giving with different implications. It would be straightforward to generalize our model to several types of charitable giving as long as this giving is fully observable, such that different types of charitable giving can be treated differently by the tax system. The realistic case with imperfect observability of charitable giving is also an important question for future research.

Let us finally return to the initial questions whether a favorable tax treatment of redistributive charitable giving from the rich to the poor is an adequate way of dealing with the increasing inequalities observed in many countries, and more generally how such giving should be treated by the tax system. Not surprisingly, as demonstrated in the present paper, these questions have no unambiguous answers. Yet, there are clearer conditional answers, which depend on the relative importance of the warm glow of giving versus the stigma of receiving charity, how much the warm glow of giving depends on giving more than others, and the size of the transaction costs (in a broad sense) of charitable giving. Another important task for future research is therefore to obtain more empirical evidence of these factors. 


\section{Appendix}

Derivation of Equation (18a)

Consider first the low-ability type. From equation (12) we can derive

$$
\operatorname{MRS}_{z, c}^{1}\left(v_{c}^{1}+v_{\Delta c}^{1}\right)=\lambda \phi \hat{v}_{z}^{2}+\gamma n^{1} w^{1} .
$$

Equation (10) implies

$$
v_{c}^{1}+v_{\Delta c}^{1}=\gamma n^{1}+\lambda \hat{v}_{c}^{2}+\lambda \hat{v}_{\Delta c}^{2}-\frac{n^{1}}{N} L_{\bar{c}} .
$$

Combining equations (A1) and (A2) yields

$$
\begin{aligned}
\operatorname{MRS}_{z, c}^{1}\left(\lambda \hat{v}_{c}^{2}+\lambda \hat{v}_{\Delta c}^{2}-\frac{n^{1}}{N} L_{\bar{c}}\right) & =\lambda \phi \hat{v}_{z}^{2}+\gamma n^{1}\left(w^{1}-M R S_{z, c}^{1}\right), \\
& =\lambda \phi \hat{v}_{z}^{2}+\gamma n^{1} T_{w l}^{2} w^{1}
\end{aligned}
$$

where in the last step we have used the private optimum condition for labor supply, i.e., equation (5). From equation (1) follows that for each type (including the mimicker)

$$
v_{\Delta c}^{i}=\alpha^{i}\left(v_{c}^{i}+v_{\Delta c}^{i}\right),
$$

which substituted into equation (15) implies

$$
L_{\bar{c}}=-\alpha^{1}\left(v_{c}^{1}+v_{\Delta c}^{1}\right)-(\delta+\lambda) \alpha^{2}\left(v_{c}^{2}+v_{\Delta c}^{2}\right)+\lambda \hat{\alpha}^{2}\left(\hat{v}_{c}^{2}+\hat{v}_{\Delta c}^{2}\right) .
$$

Note also that equation (11) can be rearranged such that

$$
(\delta+\lambda)\left(v_{c}^{2}+v_{\Delta c}^{2}\right)=\gamma n^{2}-\frac{n^{2}}{N} L_{\bar{c}} .
$$

Substituting equations (A2) and (A6) into equation (A5) yields

$$
\begin{aligned}
L_{\bar{c}} & =-\alpha^{1}\left(\gamma n^{1}+\lambda\left(\hat{v}_{c}^{2}+\hat{v}_{\Delta c}^{2}\right)-\frac{n^{1}}{N} L_{\bar{c}}\right)-\alpha^{2}\left(\gamma n^{2}-\frac{n^{2}}{N} L_{\bar{c}}\right)+\lambda \hat{\alpha}^{2}\left(\hat{v}_{c}^{2}+\hat{v}_{\Delta c}^{2}\right) \\
& =\bar{\alpha} L_{\bar{c}}-\bar{\alpha} \gamma N+\lambda\left(\hat{v}_{c}^{2}+\hat{v}_{\Delta c}^{2}\right)\left(\hat{\alpha}^{2}-\alpha^{1}\right) \\
& =-\gamma N \frac{\bar{\alpha}}{1-\bar{\alpha}}+\lambda\left(\hat{v}_{c}^{2}+\hat{v}_{\Delta c}^{2}\right) \frac{\hat{\alpha}^{2}-\alpha^{1}}{1-\bar{\alpha}}
\end{aligned}
$$

where we have used equation (16). Solving for the optimal marginal income tax rate in equation (3) and substituting equation (A7) then imply 


$$
\begin{aligned}
T_{w l}^{1} & =\frac{M R S_{z, c}^{1}}{\gamma n^{1} w^{1}}\left(\lambda \hat{v}_{c}^{2}+\lambda \hat{v}_{\Delta c}^{2}-\frac{n^{1}}{N} L_{\bar{c}}\right)-\frac{\lambda \phi \hat{v}_{z}^{2}}{\gamma n^{1} w^{1}} \\
& =\frac{M R S_{z, c}^{1}}{\gamma n^{1} w^{1}}\left(\lambda \hat{v}_{c}^{2}+\lambda \hat{v}_{\Delta c}^{2}-\frac{n^{1}}{N}\left(-\gamma N \frac{\bar{\alpha}}{1-\bar{\alpha}}+\lambda\left(\hat{v}_{c}^{2}+\hat{v}_{\Delta c}^{2}\right) \frac{\hat{\alpha}^{2}-\alpha^{1}}{1-\bar{\alpha}}\right)\right)-\frac{\lambda \phi \hat{v}_{z}^{2}}{\gamma n^{1} w^{1}}, \\
& =\frac{\lambda \hat{u}_{c}^{2}}{\gamma n^{1} w^{1}}\left(M R S_{z, c}^{1}-\phi M \hat{R} S_{z, c}^{1}\right)+\frac{M R S_{z, c}^{1}}{w^{1}}\left(\frac{\bar{\alpha}}{1-\bar{\alpha}}-\frac{\lambda\left(\hat{v}_{c}^{2}+\hat{v}_{\Delta c}^{2}\right)}{\gamma N} \frac{\hat{\alpha}^{2}-\alpha^{1}}{1-\bar{\alpha}}\right) \\
& =\tau^{1}+\frac{M R S_{z, c}^{1}}{w^{1}}\left(\frac{\bar{\alpha}}{1-\bar{\alpha}}-\frac{\alpha^{d}}{1-\bar{\alpha}}\right)
\end{aligned}
$$

where

$$
\tau^{1}=\frac{\lambda \hat{u}_{c}^{2}}{\gamma n^{1} w^{1}}\left(M R S_{z, c}^{1}-\phi M \hat{R} S_{z, c}^{1}\right)
$$

is the policy rule for marginal income taxation for type 1 individuals in the original Stiglitz (1982) model, in which there are no relative consumption concerns. Let us finally again use the private optimum condition, equation (5), in equation (A8) in order to obtain

$$
T_{w l}^{1}=\tau^{1}+\left(1-T_{w l}^{1}\right)\left(\frac{\bar{\alpha}}{1-\bar{\alpha}}-\frac{\alpha^{d}}{1-\bar{\alpha}}\right) .
$$

Solving for $T_{w l}^{1}$ and re-arranging gives equation (18a) for type 1 individuals. Equation (18) for type 2 individuals is derived similarly, in which $\tau^{2}=0$.

\section{Proof of Propositions 1 and 2}

Consider first the proof of Proposition 2. From the individual optimum condition for charity, equation (6), it follows that

$$
T_{g}^{2}=\frac{v_{g}^{2}+v_{\Delta g}^{2}}{v_{c}^{2}+v_{\Delta c}^{2}}-1-\mu_{g}\left(g^{2}\right)=\frac{v_{g}^{2} \frac{v_{g}^{2}+v_{\Delta g}^{2}}{v_{g}^{2}}}{v_{c}^{2}+v_{\Delta c}^{2}}-1-\mu_{g}\left(g^{2}\right)=\frac{1}{1-\beta^{2}} \frac{v_{g}^{2}}{v_{c}^{2}+v_{\Delta c}^{2}}-1-\mu_{g}\left(g^{2}\right) \text { (A10) }
$$

where we used equation (17) in the last step. By using the social first-order condition for charitable giving in equation (14), we can then derive

$$
v_{g}^{2}=\frac{v_{g}^{1}+\gamma n^{1} \mu_{g}\left(g^{2}\right)-\lambda \hat{v}_{g}^{2}}{\delta+\lambda} \frac{n^{2}}{n^{1}} .
$$

The social first-order condition for consumption among type 2 individuals, equation (11), implies 


$$
\begin{aligned}
v_{c}^{2}+v_{\Delta c}^{2} & =\frac{\gamma n^{2}-\frac{n^{2}}{N} L_{\bar{c}}}{\delta+\lambda}=\frac{\gamma n^{2}+\frac{n^{2}}{N}\left(\gamma N \frac{\bar{\alpha}}{1-\bar{\alpha}}-\lambda\left(\hat{v}_{c}^{2}+\hat{v}_{\Delta c}^{2}\right) \frac{\hat{\alpha}^{2}-\alpha^{1}}{1-\bar{\alpha}}\right)}{\delta+\lambda} . \\
& =\frac{1}{1-\bar{\alpha}} \frac{\gamma n^{2}}{\delta+\lambda}\left(1-\alpha^{d}\right)
\end{aligned}
$$

Substituting equations (A11) and (A12) into equation (A10) then gives

$$
\begin{aligned}
T_{g}^{2} & =\frac{1-\bar{\alpha}}{1-\alpha^{d}} \frac{v_{g}^{1}+\gamma n^{1} \mu_{g}\left(g^{2}\right)-\lambda \hat{v}_{g}^{2}}{\gamma n^{1}\left(1-\beta^{2}\right)}-\mu_{g}\left(g^{2}\right)-1 \\
& =\frac{1-\bar{\alpha}}{1-\alpha^{d}} \frac{v_{g}^{1}-\lambda \hat{v}_{g}^{2}}{\gamma n^{1}\left(1-\beta^{2}\right)}+\frac{1-\bar{\alpha}}{1-\alpha^{d}} \frac{\mu_{g}\left(g^{2}\right)}{1-\beta^{2}}-\mu_{g}\left(g^{2}\right)-1 \\
& =\frac{1-\bar{\alpha}}{1-\alpha^{d}} \frac{v_{g}^{1}-\lambda \hat{v}_{g}^{2}}{\gamma n^{1}\left(1-\beta^{2}\right)}+\mu_{g}\left(g^{2}\right)\left(\frac{1-\bar{\alpha}}{1-\alpha^{d}} \frac{1}{1-\beta^{2}}-\frac{1-\alpha^{d}}{1-\alpha^{d}} \frac{1-\beta^{2}}{1-\beta^{2}}\right)-1 . \\
& =\frac{1-\bar{\alpha}}{1-\alpha^{d}} \frac{v_{g}^{1}-\lambda \hat{v}_{g}^{2}}{\gamma n^{1}\left(1-\beta^{2}\right)}-\frac{\bar{\alpha}-\alpha^{d}-\beta^{2}\left(1-\alpha^{d}\right)}{\left(1-\alpha^{d}\right)\left(1-\beta^{2}\right)} \mu_{g}\left(g^{2}\right)-1 \\
& =\frac{1-\bar{\alpha}}{1-\alpha^{d}} \frac{v_{g}^{1}-\lambda \hat{v}_{g}^{2}}{\gamma n^{1}\left(1-\beta^{2}\right)}+\left[\frac{1-\bar{\alpha}}{\left(1-\alpha^{d}\right)\left(1-\beta^{2}\right)}-1\right] \mu_{g}\left(g^{2}\right)-1
\end{aligned}
$$

Let us finally eliminate $\gamma n^{1}$. Solving equation (10) for $\gamma n^{1}$ gives

$$
\begin{aligned}
\gamma n^{1} & =v_{c}^{1}+v_{\Delta c}^{1}-\lambda \hat{v}_{c}^{2}-\lambda \hat{v}_{\Delta c}^{2}+\frac{n^{1}}{N} L_{\bar{c}} \\
& =v_{c}^{1}+v_{\Delta c}^{1}-\lambda \hat{v}_{c}^{2}-\lambda \hat{v}_{\Delta c}^{2}-\gamma n^{1} \frac{\bar{\alpha}-\alpha^{d}}{1-\bar{\alpha}}
\end{aligned}
$$

Now, using $v_{c}^{1}+v_{\Delta c}^{1}=v_{c}^{1} /\left(1-\alpha^{1}\right)$ and $\hat{v}_{c}^{2}+\hat{v}_{\Delta c}^{2}=\hat{v}_{c}^{2} /\left(1-\hat{\alpha}^{2}\right)$, and then collecting the $\gamma n^{1}-$ terms, equation (A14) can be written as

$$
\gamma n^{1}=\frac{1-\bar{\alpha}}{1-\alpha^{d}}\left[v_{c}^{1} /\left(1-\alpha^{1}\right)-\lambda \hat{v}_{c}^{2} /\left(1-\hat{\alpha}^{2}\right)\right] .
$$

Substituting equation (A15) into equation (A13) gives equation (23) in Proposition 2. Equation (20) in Proposition 1 follows as the special case where $\mu_{g}\left(g^{2}\right)=0$.

\section{Proof of Proposition 3}

Consider first the marginal income tax formula for the low-ability type. Combining equations (30) and (31) gives

$$
\frac{u_{z}^{2}}{u_{c}^{2}}\left[\lambda \hat{u}_{c}^{2}+\gamma n^{1}-L_{\bar{c}} \frac{n^{1}}{N}\right]=\lambda \phi \hat{u}_{z}^{2}+\gamma n^{1} w^{1} .
$$

By using $w^{1}-u_{z}^{1} / u_{c}^{1}=w^{1} T_{w l}^{1}$ in equation (A16) and then solving for $T_{w l}^{1}$, we can derive 


$$
T_{w l}^{1}=\frac{\lambda \hat{u}_{c}^{2}}{\gamma n^{1} w^{1}}\left(\frac{u_{z}^{1}}{u_{c}^{1}}-\phi \frac{\hat{u}_{z}^{2}}{\hat{u}_{c}^{2}}\right)-\frac{u_{z}^{1}}{u_{c}^{1}} \frac{L_{\bar{c}}}{w^{1} \gamma N},
$$

which is equation (36a).

Turning to the marginal income tax formula for the high-ability type, we can similarly combine equations (32) and (33) to derive

$$
\frac{u_{z}^{2}}{u_{c}^{2}}\left[\gamma n^{2}-L_{\bar{c}} \frac{n^{2}}{N}-L_{g^{2}} \frac{\partial g^{2}}{\partial c^{2}}\right]=\gamma n^{2} w^{2}-L_{g^{2}} \frac{\partial g^{2}}{\partial z^{2}} .
$$

Using $w^{2}-u_{z}^{2} / u_{c}^{2}=w^{2} T_{w l}^{2}$ in equation (A18) and solving for $T_{w l}^{2}$ gives

$$
T_{w l}^{2}=-\frac{u_{z}^{2}}{u_{c}^{2}} \frac{L_{\bar{c}}}{w^{2} \gamma N}+\frac{L_{g}}{\gamma w^{2} n^{2}}\left(\frac{\partial g^{2}}{\partial z^{2}}-\frac{u_{z}^{2}}{u_{c}^{2}} \frac{\partial g^{2}}{\partial c^{2}}\right),
$$

which is equation (36b)

To derive equation (35b), we use $u_{\bar{c}}^{i}=-\alpha^{i} u_{c}^{i}$ for $i=1,2$ and $\hat{u}_{\bar{c}}^{2}=-\hat{\alpha}^{2} \hat{u}_{c}^{2}$. Substituting into equation (34a) gives

$$
L_{\bar{c}}=-\alpha^{1} u_{c}^{1}-(\delta+\lambda) \alpha^{2} u_{c}^{2}+\lambda \hat{\alpha}^{2} \hat{u}_{c}^{2}+L_{g} \frac{\partial g^{2}}{\partial \bar{c}} .
$$

Solving equation (31) for $u_{c}^{1}$ and equation (33) for $(\delta+\lambda) u_{c}^{2}$, respectively, such that

$$
\begin{aligned}
& u_{c}^{1}=\lambda \hat{u}_{c}^{2}+\gamma n^{1}-L_{\bar{c}} \frac{n^{1}}{N} \\
& (\delta+\lambda) u_{c}^{2}=\gamma n^{2}-L_{\bar{c}} \frac{n^{2}}{N}-L_{g^{2}} \frac{\partial g^{2}}{\partial c^{2}},
\end{aligned}
$$

and substituting into equation (A20) implies

$$
\begin{aligned}
L_{\bar{c}} & =-\alpha^{1}\left(\lambda \hat{u}_{c}^{2}+\gamma n^{1}-L_{\bar{c}} \frac{n^{1}}{N}\right)-\alpha^{2}\left(\gamma n^{2}-L_{\bar{c}} \frac{n^{2}}{N}-L_{g^{2}} \frac{\partial g^{2}}{\partial c^{2}}\right) . \\
& +\lambda \hat{\alpha}^{2} \hat{u}_{c}^{2}+L_{g} \frac{\partial g^{2}}{\partial \bar{c}}
\end{aligned}
$$

Collecting $L_{\bar{c}}$-terms and rearranging gives

$$
\begin{aligned}
L_{\bar{c}}\left(1-\frac{n^{1} \alpha^{1}+n^{2} \alpha^{2}}{N}\right) & =-\gamma\left(n^{1} \alpha^{1}+n^{2} \alpha^{2}\right)+\lambda \hat{u}_{c}^{2}\left(\hat{\alpha}^{2}-\alpha^{1}\right) \\
& +L_{g^{2}}\left(\frac{\partial g^{2}}{\partial \bar{c}}+\alpha^{2} \frac{\partial g^{2}}{\partial c^{2}}\right)
\end{aligned} .
$$


Finally, by using the expression for $L_{g^{2}}$ in equation (35a) and substituting into equation (A22), we obtain equation (35b).

\section{References}

Abel, A.B., (2005) Optimal Taxation When Consumers Have Endogenous Benchmark Levels of Consumption. Review of Economic Studies 72, 1-19.

Akerlof, G.A., (1997) Social Distance and Social Decisions. Econometrica 65, 1005-1028.

Andreoni, J., (1989) Giving with Impure Altruism: Applications to Charity and Ricardian Equivalence. Journal of Political Economy 97, 1447-1458.

Andreoni, J., (1990) Impure Altruism and Donations to Public Goods: A Theory of WarmGlow Giving. Economic Journal 100, 464-77.

Aronsson, T., O. Johansson-Stenman, (2008) When the Joneses' Consumption Hurts: Optimal Public Good Provision and Nonlinear Income Taxation. Journal of Public Economics 92, 986-997.

Aronsson, T., O, Johansson-Stenman, (2010) Positional Concerns in an OLG Model: Optimal Labor and Capital Income Taxation. International Economic Review 51, 1071-1095.

Aronsson, T., O. Johansson-Stenman (2018) Paternalism Against Veblen: Optimal Taxation and Non-Respected Preferences for Social Comparisons. American Economic Journal: Economic Policy 10, 39-76.

Aronsson, T., O. Johansson-Stenman, and R. Wendner (2019) Charity, Status, and Optimal Taxation: Welfarist and Paternalist Approaches. Working paper. Umeå Economic Studies No. 959.

Atkinson, A.B., (1976) The Income Tax Treatment of Charitable Contributions. In: Grieson, R. (Ed.), Public and Urban Economics: Essays in the Honor of William S. Vickrey. D.C. Heath, New York.

Auten, G., H. Sieg, C.T. Clotfelter, (2002) Charitable Giving, Income and Taxes: An Analysis of Panel Data. American Economic Review 92, 371-382.

Baumberg, B., (2016) The Stigma of Claiming Benefits: A Quantitative Study. Journal of Social Policy 45, 181-199.

Besley, T., S. Coate, (1992) Understanding welfare stigma: Taxpayer resentment and statistical discrimination, Journal of Public Economics 48, 165-184.

Blanchflower, D.G., A.J. Oswald, (2004) Well-Being Over Time in Britain and the USA. Journal of Public Economics 88, 1359-1386. 
Blumkin, T., E. Sadka, (2007) A case for taxing charitable donations. Journal of Public Economics 91 (7-8), 1555-1564.

Boskin, M.J., E. Sheshinski, (1978) Individual Welfare Depends Upon Relative Income. Quarterly Journal of Economics 92, 589-601.

Bowles, S., Y. Park, (2005) Emulation, Inequality, and Work Hours: Was Thorsten Veblen Right? Economic Journal 115, F397-F412.

Carlsson, F., O. Johansson-Stenman, P. Martinsson, (2007) Do You Enjoy Having More Than Others? Survey Evidence of Positional Goods. Economica 74, 586-598.

Cartwright, E., A. Patel, (2013) How Category Reporting can Improve Fundraising. Journal of Economic Behavior and Organization 87, 73-90.

Chase, E., R. Walker, (2013) The Co-Construction of Shame in the Context of Poverty: Beyond a Threat to the Social Bond. Sociology 47, 739-754.

Clark, A.E., A.J. Oswald, (1994) Unhappiness and Unemployment, Economic Journal 104, 648-659.

Clark, A., C. Senik, (2010) Who Compares to Whom? The Anatomy of Income Comparisons in Europe. Economic Journal 120, 573-594.

Clotfelter, C.T. (Ed.), (1992) Who Benefits from the Nonprofit Sector. The University of Chicago Press, Chicago.

Clotfelter, C.T., (2014) Charitable Giving and Tax Policy in the U.S. In: Fack, G., C. Landais (Eds.), Charitable Giving and Tax Policy: A Historical and Comparative Perspective. Oxford, Oxford University Press.

DellaVigna, S., J. List, U. Malmendier, (2012) Testing for Altruism and Social Pressure in Charitable Giving. Quarterly Journal of Economics 127, 1-56.

Diamond, P., (2006) Optimal Tax Treatment of Private Contributions for Public Goods with and Without Warm-Glow Preferences. Journal of Public Economics 90, 897-919.

Dupor, B., W.F. Liu, (2003) Jealousy and Overconsumption. American Economic Review 93, 423-428.

Easterlin, R.A., (2001) Income and Happiness: Towards a Unified Theory. Economic Journal $111,465-484$.

Eckerstorfer, P., R. Wendner (2013) Asymmetric and Non-atmospheric Consumption Externalities, and Efficient Consumption Taxation, Journal of Public Economics 106, $42-56$.

Feldstein, M., (1980) A Contribution to the Theory of Tax Expenditures: The Case of Charitable Giving. In: Aaron, H. J., and M. J. Boskin (Eds.), The Economics of 
Taxation, Essays in Honor of Joseph Peckman, 99-122. Brookings Institution, Washington, D.C.

Ferrer-i-Carbonell, A., (2005) Income and Well-being: An Empirical Analysis of the Comparison Income Effect. Journal Public Economics 89, 997-1019.

Galí, J., (1994) Keeping Up with the Joneses: Consumption Externalities, Portfolio Choice and Asset Prices. Journal of Money, Credit, and Banking 26, 1-8.

Glazer, A., K. Konrad, (1996) A Signaling Explanation for Charity. American Economic Review 86, 1019-1028.

Harbaugh, W., (1998a) What do Donations Buy? A Model of Philanthropy Based on Prestige and Warm Glow. Journal of Public Economics 67, 269-284.

Harbaugh, W., (1998b) The Prestige Motive for Making Charitable Transfers. American Economic Review 88, 277-282.

Harsanyi, J. (1982) Morality and the Theory of Rational Behavior. In Utilitarianism and Beyond, edited by Sen, A. and Williams, B. Cambridge: Cambridge University Press.

Johansson-Stenman, O., F. Carlsson, D. Daruvala, (2002) Measuring Future Grandparents' Preferences for Equality and Relative Standing. Economic Journal 112, 362-383.

Kanbur, R., M. Tuomala. (2013) Relativity, Inequality and Optimal Nonlinear Income Taxation. International Economic Review 54, 1199-1217.

Kaplow, L., (1995) A note on subsidizing gifts. Journal of Public Economics 58, 469-477.

Kaplow, L., (1998) Tax policy and gifts. American Economic Review: Papers and Proceedings 88, 283-288.

Kleven, H., W. Kopczuk, (2011) Transfer program complexity and the takeup of social benefits. American Economic Journal: Economic Policy 3, 54-90.

Layard, R., (1980) Human Satisfaction and Public Policy. Economic Journal 90, 737-750.

Moffit, R., (1983) An economic model of welfare stigma, American Economic Review 75, 1023-1035.

Oswald, A., (1983) Altruism, Jealousy and the Theory of Optimal Non-Linear Taxation. Journal of Public Economics 20, 77-87.

Reinstein, D., G. Riener, (2012) Decomposing Desert and Tangibility Effects in a Charitable Giving Experiment. Experimental Economics 15, 229-240.

Roberts, R.D., (1987) Financing Public Goods. Journal of Political Economy 95, 420-437.

Sen, A.K., (1983) Development: Which Way Now? The Economic Journal 93, 745-762.

Sen, A.K., (1999) Development as Freedom (ed. A. Knopf), New York: Oxford University Press. 
Saez, E., (2004) The Optimal Treatment of Tax Expenditures. Journal of Public Economics $88,2657-2684$.

Saez, E., and Zucman, G. (2016) Wealth Inequality in the United States since 1913: Evidence from Capitalized Income Tax Data. Quarterly Journal of Economics, 131, 519-578.

Solnick, S., D. Hemenway, (2005) Are Positional Concerns Stronger in Some Domains than in Others? American Economic Review, papers and proceedings 45, 147-151.

Stiglitz, J.E., (1982) Self-Selection and Pareto Efficient Taxation. Journal of Public Economics 17, 213-240.

Warr, P., (1982). Pareto optimal redistribution and private charity. Journal of Public Economics 19, 131-138.

Wendner, R., L.H. Goulder, (2008) Status Effects, Public Goods Provision, and the Excess Burden. Journal of Public Economics 92, 1968-1985. 